\title{
Evaluation of Concepts for Monitored Retrievable Storage of Spent Nuclear Fuel and High-Level Radioactive Waste
}

\author{
M. B. Triplett \\ R. I. Smith
}

April 1984

Prepared for the U.S. Department of Energy under Contract DE-AC06-76RLO 1830

Pacific Northwest Laboratory Operated for the U.S. Department of Energy by Battelle Memorial Institute 


\title{
DISCLAIMER
}

This report was prepared as an account of work sponsored by an agency of the United States Government. Neither the United States Government nor any agency thereof, nor any of their employees, makes any warranty, express or implied, or assumes any legal liability or responsibility for the accuracy, completeness, or usefulness of any information, apparatus, product, or process disclosed, or represents that its use would not infringe privately owned rights. Reference herein to any specific commercial product, process, or service by trade name, trademark, manufacturer, or otherwise, does not necessarily constitute or imply its endorsement, recommendation, or favoring by the United States Government or any agency thereof. The views and opinions of authors expressed herein do not necessarily state or reflect those of the United States Government or any agency thereof.

\author{
PACIFIC NORTHWEST LABORATORY \\ operated by \\ BATTELLE \\ for the \\ UNITED STATES DEPARTMENT OF ENERGY \\ under Contract DE-AC06-76RLO 1830
}

\begin{tabular}{|c|c|}
\hline \multicolumn{2}{|c|}{ Printed in the United States of America } \\
\hline \multicolumn{2}{|c|}{ Available from } \\
\hline \multirow{4}{*}{\multicolumn{2}{|c|}{$\begin{array}{c}\text { National Technical Information Service } \\
\text { United States Department of Commerce } \\
5285 \text { Port Royal Road } \\
\text { Springfield, Virginia } 22161\end{array}$}} \\
\hline & \\
\hline & \\
\hline & \\
\hline \multirow{2}{*}{\multicolumn{2}{|c|}{$\begin{array}{l}\text { NTIS Price Codes } \\
\text { Microfiche } \mathrm{A} 01\end{array}$}} \\
\hline & \\
\hline \multicolumn{2}{|c|}{ Printed Copy } \\
\hline & Price \\
\hline Pages & Codes \\
\hline $001-025$ & A02 \\
\hline 026-050 & $\mathrm{A} 03$ \\
\hline 051-075 & AO4 \\
\hline $076-100$ & A05 \\
\hline $101-125$ & A06 \\
\hline $126-150$ & A07 \\
\hline $151-175$ & $A 0 B$ \\
\hline $176-200$ & A09 \\
\hline $201-225$ & A010 \\
\hline $226-250$ & A011 \\
\hline $251-275$ & A012 \\
\hline $276-300$ & $\wedge 013$ \\
\hline
\end{tabular}


EVALUATION OF CONCEPTS FOR

MONITORED RETR IEVABLE STORAGE

OF SPENT NUCLEAR FUEL AND

HIGH-LEVEL RADIDACTIVE WASTE

M. B. Triplett

R. 1. Smith

Apri1 1984

Work supported by the

U.S. Department of Energy

under Contract DE-AC06-76RLO0 1830

Pacific Northwest Laboratory

Richland, Washington 99352 


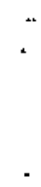




\section{SUMMARY}

The Nuclear Waste Policy Act (NWPA) of 1982 directs the Department of Energy (DOE) to present to Congress on or before June 1, 1985, a proposal to construct one or more monitored retrievable storage (MRS) facilities for spent commercial nuclear fuel and high-level waste. The NWPA further specified many of the activities that DOE was to carry out in preparing the proposal and also much of the content of the proposal. To comply with the requirements of the NWPA, DOE will conduct further design on two potential concepts for MRS. One of these concepts, the primary concept, will be taken to greater design detail than the other. An early step toward the MRS proposal to Congress is the selection of the two concepts for further design. This report describes the evaluation of alternative MRS concepts conducted by the Pacific Northwest Laboratory (PNL) in support of DOE's selection of the primary and alternate concepts.

The primary mission selected by DOE for the MRS system is to provide an alternative means of storage in the event that the repository program is delayed. The MRS concepts considered were the eight concepts included in the MRS Research and Development Report to Congress (DOE 1983). These concepts are listed below.

- Metal cask (stationary and transportable)

- Concrete cask (sealed storage cask)

- Concrete cask-in-trench

- Field drywell
- Tunnel dryweil

- Open cycle vault

- Closed cycle vault

- Tunnel rack vault

MRS concepts have been studied extensively in the past 15 to 20 years. Unfortunately, the various results from these previous studies are difficult to compare because of inconsistent assumptions for throughput rates, storage capacities, and projected facility lifetimes. To achieve a more equitable comparison of the concepts, conceptual design analyses were performed for the candidate concepts using a common set of design requirements specified in consideration of the MRS mission. 
An important consideration in the design of an MRS facility and selection of appropriate storage concepts is that the MRS system should not constrain the operation of the total waste management system. Rather, the MRS system should be designed to be integrated into the total system and should readily accommodate the operational requirements of at-reactor storage, transportation, and the repositories. In recognition of this need, a common interface with the rest of the waste management system was defined so that interactions with transportation and at-reactor storage and handling components were common across all concepts. Consequently, concepts were compared primarily upon the relative performance of the storage units on seven criteria that together reflect the ability of the concepts to satisfy the MRS mission requirements. These criteria were:

- safety and licensing

- environmental impacts

- socioeconomic impacts

- siting requirements
- cost

- concept maturity

- flexibility

Evaluations of the candidate concepts indicate that all of the concepts could satisfactorily serve in an MRS facility. However, using the above criteria, the two concepts recommended for further design studies are the field drywell and the concrete cask.

It is recognized that the transportable metal storage cask may be used to supplement at-reactor storage until such time as the repository or MRS becomes available. Consequently, a hybrid storage facility may be desirable (e.g., one using concrete cask or field drywells, with the capability of receiving and storing the transportable cask). Both the field drywell and the concrete cask concepts can easily accommodate the transportable cask. Further design efforts will ensure the compatibility of the MRS designs with the transportable cask. 


\section{CONTENTS}

SUMMARY

1.0 INTRODUCTION.

2.0 EVALUATION APPROACH/PROCESS AND ASSUMPTIONS

2.1 EVALUATION PROCESS OVERVIEW....................... 2.1

2.2 EVALUATION PROCESS STEPS........................ 2.2

2.2.1 Step 1: Develop Ranking Criteria............... 2.2

2.2.2 Step 2: Assign Weights to Evaluation Criteria....... 2.5

2.2.3 Step 3: Assemble Normalized Concept Data........... 2.6

2.2.4 Step 4: Rank Concepts for Each Criterion............ 2.7

2.2.5 Step 5: Obtain Composite Ranking and Conduct

Sensitivity Analysis.................. 2.8

2.2.6 Step 6: Conduct Pairwise Comparisons............. 2.9

2.2.7 Step 7: Recominend Two Preferred Concepts........... 2.9

3.0 NORMALIZATION OF CANDIDATE MRS CONCEPTS................. 3.1

3.1 CANDIDATE MRS CONCEPTS $\ldots \ldots \ldots \ldots \ldots \ldots \ldots \ldots \ldots \ldots \ldots \ldots \ldots \ldots \ldots \ldots \ldots \ldots$

3.2 FUNCTIONAL CRITERIA AND SYSTEM REQUIREMENTS ............ 3.2

3.3 GENERIC RECEIVING AND HANDLING FACILITY $\ldots \ldots \ldots \ldots \ldots \ldots \ldots \ldots . \quad 3.4$

3.4 INFORMATION ON STDRAGE CONCEPTS................. 3.5

3.4.1 Metal Storage Cask....................... 3.6

3.4 .2 Metal Cask............................... 3.8

3.4 .3 Concrete Cask........................... 3.9

3.4.4 Cask-in-Trench.............................. 3.11

3.4 .5 Field Drywell.............................. 3.1

3.4 .6 Tunnel Drywe11......................... 3.13

3.4 .7 Open Cycle Vault........................ 3.14 
3.4.8 Closed Cycle Vault.............................. 3.16

3.4 .9 Tunnel Rack Vault........................... 3.18

4.0 RANKING RESULTS BY CRITERION............................. 4.1

4.1 SAFETY/LICENSING CRITERION.......................... 4.1

4.1.1 Ease of Conformance with Licensing Requirements....... 4.2

4.1 .2 Criticality Safety.............................. 4.3

4.1 .3 Monitorability,.............................. 4.3

4.1 .4 Containment Integrity......................... 4.4

4.1.5 Accident/Malfunction Recoverability............... 4.4

4.1.6 Design Testing............................... 4.5

4.1.7 Penetrability and Security...................... 4.5

4.1 .8 Accountability............................... 4.6

4.1.9 Previous Licensing Experience.................... 4.6

4.1 .10 Ordinal Ranking for Safety/Licensing............. 4.6

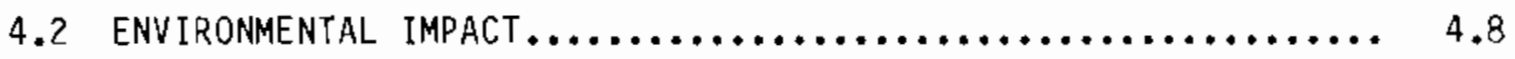

4.2.1 Radioactivity Releases........................ 4.8

4.2.2 Exclusion Area Size........................... 4.9

4.2.3 Recoverability of Area.......................... 4.10

4.2.4 Ordinal Ranking for Environmental Impact........... 4.10

4.3 SOCIOECONOMIC IMPACTS $\ldots \ldots \ldots \ldots \ldots \ldots \ldots \ldots \ldots \ldots \ldots \ldots \ldots \ldots \ldots \ldots \ldots, 4.11$

4.3 .1 Acceptability................................ 4.11

4.3.2 Aesthetic Considerations $. . . \ldots \ldots \ldots \ldots \ldots \ldots \ldots \ldots, 4.12$

4.3 .3 Labor Force Impact........................... 4.12

4.3.4 Economic Impact........................... 4.13

4.3.5 Ordinal Ranking for Socioeconomic Impact............ 4.13

4.4 SITING REQUIREMENTS $\ldots \ldots \ldots \ldots \ldots \ldots \ldots \ldots \ldots \ldots \ldots \ldots \ldots \ldots \ldots \ldots \ldots \ldots \ldots, 4.13$ 
4.4.1 Land Requirements............................. 4.14

4.4 .2 Geological Requirements........................ 4.14

4.4.3 Hydrological Requirements...................... 4.15

4.4 .4 Resource Requirements.......................... 4.15

4.4.5 Ordinal Ranking for Siting Requirements............. 4.15

4.5 COST CRITERION.................................... 4.16

4.5.1 Life-Cycle Costs............................ 4.16

4.5 .2 Cost Sensitivity $\ldots \ldots \ldots \ldots \ldots \ldots \ldots \ldots \ldots \ldots \ldots \ldots, 4.18$

4.5.3 Confidence in Cost Estimate...................... 4.18

4.5.4 Ordinal Ranking for Cost....................... 4.19

4.6 CONCEPT MATURITY CRITERION............................ 4.19

4.6 .1 Concept Development............................ 4.20

4.6.2 Research and Development Requirements.............. 4.21

4.6 .3 Conservatism Needed.......................... 4.22

4.6 .4 Deployment Time............................... 4.22

4.6 .5 Storage Retrievability........................ 4.22

4.6.6 Engineering Simplicity........................ 4.23

4.6.7 Ordinal Ranking for Concept Maturity............... 4.24

4.7 FLEXIBILITY...................................... 4.24

4.7 .1 Site Adaptability............................. 4.25

4.7.2 Expandability of Throughput Rate and Capacity......... 4.26

4.7 .3 Waste Form Sensitivity........................ 4.26

4.7.4 Heat Load Sensitivity......................... 4.27

4.7.5 Recoverability of Capital Assets.................. 4.27

4.7.6 Critical Resource Consumption.................... 4.27

4.7.7 Ordinal Ranking for Flexibility.................. 4.28 
5.0 COMPOSITE RANKING RESULT $\ldots \ldots \ldots \ldots \ldots \ldots \ldots \ldots \ldots \ldots \ldots \ldots \ldots \ldots, 5.1$

5.1 ASSignMENT OF WEIghtS to EVALUation CRITERIA.............. 5.1

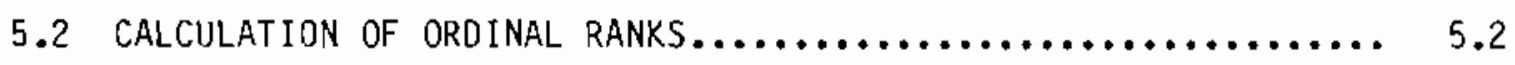

5.3 CALCUlation OF COMPOSite RANKS $\ldots \ldots \ldots \ldots \ldots \ldots \ldots \ldots \ldots \ldots, 5.4$

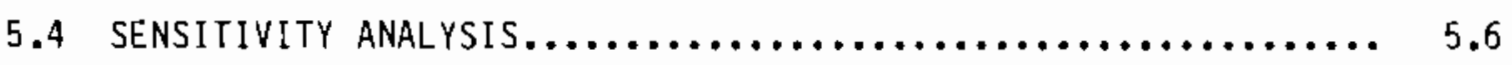

6.0 PAIRWISE COMPARISON OF CONCEPTS - FINAL RANKING $\ldots \ldots \ldots \ldots \ldots \ldots \ldots . .6 .1$

7.0 CONCLUSIONS AND RECOMMENDATIONS $\ldots \ldots \ldots \ldots \ldots \ldots \ldots \ldots \ldots \ldots \ldots \ldots, 7.1$

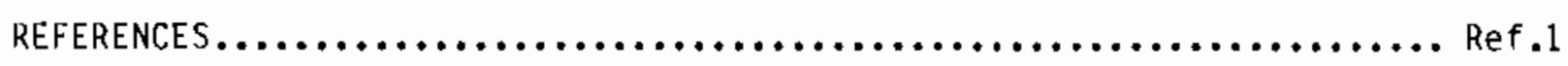




\section{FIGURES}

2.1 MRS Concept Evaluation Process........................ 2.3

3.1 Metal Storage Cask Concept......................... 3.7

3.2 Concrete Cask Concept............................ 3.10

3.3 Field Drywell Concept............................. 3.12

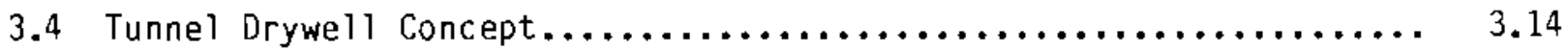

3.5 Open Cycle Vault Concept............................... 3.15

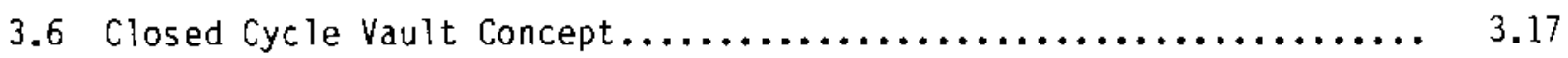

3.7 Tunnel Rack Concept.............................. 3.18

\section{$\underline{\text { TABLES }}$}

2.1 MRS Ranking Criteria and Descriptors.................. 2.4

4.1 Estimated Exclusion Area for 15,000 and 72,000 MTU MRS Facilities..................................... 4.9

4.2 Estimated Life-Cycle Costs for Candidate Concepts in Millions of Undiscounted 1983 Dollars ........................... 4.17

5.1 Ranking Results by Criterion...................... 5.5

5.2 Composite Ranking Results........................ 5.5

5.3 Sensitivity Analys is Results ...................... 5.7 



\subsection{INTRODUCTION}

In the Nuclear Waste Policy Act (NWPA) of 1982, Congress affirmed the responsibility of the Federal Government to provide for the disposal of spent fuel and high-level radioactive waste resulting from civilian nuclear activities. The disposal facility envisioned by Congress was a deep underground repository where radioactive material could be permanently emplaced with no significant risk to present or future generations. The NWPA requires the Department of Energy (DOE) to begin accepting radioactive material for disposal starting in 1998. However, in the NWPA Congress also noted that monitored retrievable storage (MRS) (a) was a safe and reliable option for the long-term storage of high-level radioactive waste or spent nuclear fuel. Although the NWPA did not describe a specific mission for MRS, DOE has identified a basic mission as a back-up to provide long-term interim storage in the event of delay in the Geologic Repository Deployment Program.

The NWPA directed DOE to submit to Congress on, or before, June 1, 1985, a proposal for the construction of one or more MRS facilities. The NWPA further specified that the proposal include, for the first such facility, at least three alternative sites and at least five alternative combinations of proposed sites and facility designs.

To develop the five combinations, at least two design concepts must be provided. There are numerous design concepts that have been proposed and analyzed for MRS. An initial hypothesis, subsequently confirmed by the present evaluation, was that at least several of these would be fully suitable for MRS, but that they would have different advantages and disadvantages in regard to satisfying the MRS mission. To focus the design effort and to make the best

(a) In an MRS facility, radioactive material is stored in shielded packages in secured areas. The storage areas and packages are monitored to detect offstandard conditions so that modifications or repairs can be made before any significant release of radioactive material to the environment could occur. Finally, the packages are retrievable so that the spent fuel or waste can be eventualiy transferred for additional processing or disposal. 
use of limited resources, an initial phase of the MRS Program was to systematically evaluate candidate concepts to support DOE's selection of two concepts (a primary and an alternate) for further design and inclusion in the proposal to Congress.

This document contains the results of the concept evaluation activity and also summarizes the factors that were considered and the rationale for the recommendation of the concepts. To aid in the selection of the concepts, DOE assigned Pacific Northwest Laboratory (PNL) the responsibility of evaluating the candidate concepts and of ensuring that there was adequate comparable information to permit a sound evaluation. As part of this activity, the designs of the candidate concepts were normalized to meet a common set of assumed design requirements, using previously published information. The design normalizations were performed by Boeing Corporation $(1983 a, b, C)$; GA Technologies, Inc. $(1984 a, b)$; and Westinghouse Electric Corporation (1983a,b,c,d). Raymond Kaiser Engineers, Inc. (1984) was responsible for developing information on the nonstorage (e.g., receiving and handing) portions of the facility that were common for all concepts.

The evaluation approach and criteria are described in Section 2. The concepts considered are described in Section 3. The relative merits of the concepts for each of the evaluation criteria are discussed in Section 4 . The ranking of the concepts considering the weights assigned to the criteria and the relative merits for each criterion are presented in Section 5 . Section 6 contains the specific advantages and disadvantages of the concepts and the bases for the final ranking recommendation. The conclusions and recommendations are presented in section 7. 


\subsection{EVALUATION APPROACH/PROCESS AND ASSUMPTIONS}

This section contains descriptions of the concept evaluation process and the steps leading to the concept recommendation. An overview of the process is provided first, followed by a more detailed discussion of each step.

\subsection{EVALUATION PROCESS OVERVIEW}

The intent of the concept evaluation process was to provide a sound basis for the selection of MRS concepts for further design study. There were three key elements of the process:

1. The candidate concepts were compared on a consistent and uniform basis. Common assumptions about the concepts were identified to ensure that all concepts had comparable operational and cost bases.

2. The relative merits of concepts were compared along dimensions relevant to the selection of MRS concepts. A set of seven criteria--each criterion defined by several descriptors--were used as the dimensions along which to compare concepts. These criteria and descriptors include those factors that are important both in selecting MRS concepts and in differentiating among the relative merits of the candidate concepts.

3. The evaluation process had to establish a sound rationale for selecting from among the candidate concepts. Previous studies had shown-and the present study confirmed--that any of the concepts would be acceptable for use in an MRS facility. Given the mission of MRS in the waste management system, however, some concepts were more desirable than others. Those reasons leading to the final ranking of concepts had to be identified.

While MRS concepts have been studied extensively in the past 15 to 20 years, the various study results are difficult to compare due to inconsistent design and operational assumptions. Past studies, therefore, did not provide a sound technical basis for selecting concepts for further design. To alleviate this problem, the candidate concepts were normalized to a common set of 
performance requirements (see Section 3.0) to provide comparable design and performance data. These data were reviewed using a structured decision process, and the relative performance of the alternative concepts for each of seven evaluation criteria was determined. To assemble these separate technical evaluations into an overall or composite recommendation, weights were assigned to the criteria to indicate their relative importance in selecting an MRS concept. The rankings by criterion and the criteria weights were combined into a composite ranking. The sensitivity of this composite ranking to changes in the criteria weights was examined to clearly separate the concepts according to their relative desirability. Each of the higher ranking concepts was compared with all other higher ranking concepts in terms of its relative advantages and disadvantages. These pairwise comparisons provided the final basis for the recommendation of the two preferred concepts for further design.

\subsection{EVALUATION PROCESS STEPS}

The MRS concept evaluation process consisted of the seven steps depicted in Figure 2.1. This figure also shows the group responsible for conducting each step. These steps are described in more detail below.

\subsubsection{Step 1: Develop Ranking Criteria}

Seven ranking criteria were chosen to provide a basis for collecting technical data on the concepts and as dimensions along which concepts could be compared. These criteria were defined by considering the aspects of MRS system performance that were most important in selecting a facility concept. A group of MRS Program staff from PNL and DOE established the criteria by identifying the important factors in the performance of an MRS facility. These factors were combined to form seven criteria. Each criterion was defined by descriptors that guided the data collection activity. The seven ranking criteria (safety/licensing, environmental impact, socioeconomic impact, siting requirements, cost, concept maturity, and flexibility) are briefly defined below and displayed along with their descriptors in Table 2.1. Expanded definitions of both the criteria and descriptors are contained in Section 4.0 . 


$\frac{\text { DOE, PNL }}{\text { Step 1: } \begin{array}{l}\text { Develop Ranking } \\ \text { Criteria }\end{array}}$
CRITERIA WEIGHTING COMMITTEE (CWC)
Step 2: $\begin{aligned} & \text { Assign Weights to } \\ & \text { Ranking Criteria }\end{aligned}$

FOUR INDEPENDENT CONTRACTORS

Step 3: Assemble Normalized Concept Data

CONCEPT RANKING COMMITTEE (CRC)

Step 4: Rank Concepts for

Each Criterion

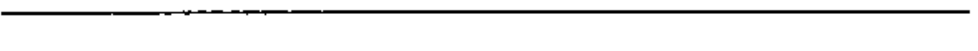

DECISION ANALYSIS STAFF

Step 5: Compute Composite Ranking and Conduct Sensitivity

Analyses

RANKING COMMITTEE

Step 6: Conduct Pairwise

Comparisons

RANKING COMPITTEE

Step 7: Recommend Two Preferred

Concepts

\section{FIGURE 2.1. MRS Concept Evaluation Process}

Safety/Licensing: MRS concepts must operate safeiy and must be licens-

Envirommental Impacts: MRS concepts must prevent unacceptable releases of radioactive materials to the environment. The environmental impact of a facil-
} able. Concepts will differ in the ease with which safe operation can be assured and licensability demonstrated. Clearer assurance of safety will facilitate the licensing process. ity will depend upon the extent of modifications to the site and the ease of returning the site to other uses once the facility is no longer required. 
TABLE 2.1. MRS Kanking Criteria and Descriptors

Safety/Licensing

Ease of Conformance with Licensing Requi rements

Criticality Safety

Monitorability

Containment Integrity

Accident/Malfunction Recoverability

Design Testing

Penetrability and Security

Accountability

Previous Licensing

Environmental Impacts

Radioactivity Releases

Exclusion Area Size

Recoverability of Area

Socioeconomic Impacts

Acceptability

Aesthetic Considerations

Labor Force Impacts

Econoric Impacts
Siting Requirements

Land Requirements

Geological Requirements

Hydrological Requirements

Resource Requirements

Cost

Life-Cycie Costs

Cost Sensitivity

Cost Estimating Confidence

Concept Maturity

Concept Development

R\&D Requirements

Conservatism Needed

Deployment Time

Storage Retrievability

Engineering Simplicity

Flexibility

Site Adaptability

Expandability of Throughput Rate and Capacity

Sensitivity to Waste Forn

Heat Load Sensitivity

Recoverability of Capital Assets

Critical Resource Consumption 
Socioeconomic Impacts: The acceptability of a given concept to the populace in the vicinity of the proposed site is influenced by public perceptions regarding, among other factors, the safety of the concept, the degree of perceived "permanence" of the installation, the appearance of the installed facility, and the impact upon the local economy.

Siting Requirements: Concepts should exhibit a degree of independence from geologic characteristics (e.g., thermal, seismic, and soil or rock chemistry) and from hydrologic characteristics (e.g., groundwater, precipitation, and flooding).

Cost: Total MRS system iife-cycle costs should be minimized. Moreover, unit storage costs should be relatively insensitive to changes in waste receipt rate, storage capacity, and waste form to be stored.

Concept Maturity: Since the MRS system would provide back-up storage in case of delays in repository deployment, preferred concepts should offer high assurance of timely deployment. Simple, well-developed, and well-understood concepts would provide this assurance.

Flexibility: Since there is uncertainty in the timing, need and operational requirements for an MRS system, concepts should have the flexibility needed to accommodate changes in the waste acceptance rate, storage capacity, waste form, and heat load. Concepts should also be easily adaptable to a variety of sites.

\subsubsection{Step 2: Assign Weights to Evaluation Criteria}

The seven criteria identified in Step 1 were not considered to be of equal significance in selecting an MRS concept. To adequately incorporate these differences into the evaluation process, numerical weights were assigned to each criterion, corresponding to its perceived relative importance in MRS concept selection. These weights were derived from data provided by the Criteria weighting Committee (CWC). The CWC consisted of six senior PNL staff selected for their broad perspective on nuclear waste management issues. These committee staff had a broad mix of relevant technical and management backgrounds including environmental, health and safety, engineering and cost. 
The committee members met to discuss the MRS mission and the evaluation criteria. These discussions served to clarify the meaning of the criteria and to highlight differences among the factors that made the criteria important in selecting an MRS concept. On the basis of these discussions, committee members individually completed matrices of pairwise comparisons indicating the relative importance of the criteria. These matrices were combined using a systematic procedure, called the Analytic Hierarchy Process (Saaty 1980), to develop the criteria weights. The CWC also clarified the meaning and interpretation to be given to the criteria and descriptors.

The results of this step are described in Section 5.0.

\subsubsection{Step 3: Assemble Normalized Concept Data}

To facilitate an equitable comparison of the concepts, a conceptual design analysis was performed for each concept by independent and experienced contractors. These contractors were selected for their previous technical evaluation work on the MRS concept designs. A common set of design requirements for storage of spent fuel was specified to factlitate this analysis. These requirements are listed in detail in Appendix $A$. The principal requirements developed with consideration of the MRS mission were:

- 15,000 MTU storage capacity

- 1,800 MTU/yr throughput rate

- consolidation of spent fuel at the MRS facility prior to storage

- throughput rate expandable to 3,000 MTU/yr

- storage capacity expandable to 72,000 MTU.

An evaluation of the same scenario for storage of equivalent quantities of HLW and its associated TRU waste from spent fuel reprocessing was also used to compare concepts. Further requirements and the candidate concepts are described in Section 3.0 .

Data from these conceptual design analyses were assembled into a format that paralleled that of the ranking criteria and their descriptors, thus facilitating the comparison of the candidate concepts. 


\subsubsection{Step 4: Rank Concepts for Each Criterion}

Using the norinalized concept data, the Concept Ranking Committee (CRC), which consisted of ten PNL technical staff knowledgeable in MRS concepts, ranked the candidate concepts from most to least preferred for each criterion. These seven rankings were constructed on the basis of the committee's judgment as to each concept's relative performance on a criterion. In arriving at these rankings, information on the relative importance of the criteria was not provided. The purposes of this step were to examine the relative merits of the concepts in a structured and systematic fashion, to produce an ordinal ranking of the concepts for each criterion and to generate a clear and concise rationale for each ranking. This rationale identified those factors that were most important in determining the ranking for each criterion. In some cases, these factors consisted of particular descriptors or subdescriptors. In other cases, factors not directly mentioned in the descriptors (e.g., presence of tunnels or use of the ground, for radiation shielding) were identified as most important in the ranking decision.

The normalized concept data were grouped according to the seven criteria to facilitate the comparison of the concepts. Within these seven criteria were a total of 35 descriptors, and within these descriptors were 85 subdescriptors. To carefully consider the relative merits of the candidate concepts, their relative advantages and disadvantages were first compared along each of the descriptors. Next, each comittee member ordered the concepts from most to least preferred for each of the criteria. Members were free to use any method for obtaining this rank ordering, with the restriction that the order be expressed from 1 to 9 with 1 being best. Ties among the concept ranks were a) lowed.

The members' assessments by descriptor were tabulated and the CRC met to elininate differences in both the interpretation of the descriptors and the understanding of the concept data. Differences were allowed, however, in assessment of the relative importance of the various descriptors and subdescriptors used to determine the overall ranking for a criterion. 
The members' rankings were combined to yield a final rank ordering of concepts for each criterion. These member rankings were combined using the Minimum Distance Calculation (Cook and Seiford 1982). This calculation tended to assign equal rank to concepts with roughly equivalent overall performance. Concepts of equal rank usually differed to some degree in performance on one or more aspects of a criterion. However, differences between concepts of equal rank were less significant than differences between concepts of unequal rank. The final rankings for each criterion tended to indicate significant differences between concepts. Each committee member's ranking was given equal weight in this calculation.

The results of these rankings are described in Section 4.0 .

\subsubsection{Step 5: Obtain Composite Ranking and Conduct Sensitivity Analysis}

In Step 5, the seven rank orderings from Step 4, one for each criterion, were combined with the criteria weights from Step 2 to obtain a composite ranking. Section 5.0 contains the results of the composite ranking step. The Minimum Distance Calculation (Cook and Sejford 1982) was used to combine the ranking by criterion into the composite ranking. As previously noted, this calculation tended to assign equal rank to concepts of roughly equivalent overall performance. Thus, some concepts were tied in the composite ranking. Concepts of unequal rank tended to have significant differences in their overall performance, while concepts of equal rank tended to have only very smali performance differences. Differences between groups of concepts having unequal rank were more significant than differences within groups of equal rank.

The sensitivity of the composite ranking to variations in the criteria weights was examined. As a result of this analysis, several concepts were shown to be clearly less desirable for an MRS facility, i.e., these concepts ranked low over a wide range of assumed criteria weights. The remaining topranked concepts were judged to have only minor differences in their overall suitability as an MRS facility. Consequently, the composite ranking and associated sensitivity analysis served to eliminate some concepts from further consideration but left a number of concepts essentially tied in the ranking. In order to provide a firm basis for the final concept recommendations, another analysis process using an additional perspective on the concepts was included in Step 6. 


\subsubsection{Step 6: Conduct Pairwise Comparisons}

The top concepts identified in Step 5 have differences in their relative merits as an MRS facility. Each concept had some advantages and disadvantages when compared with the other concepts. The purposes of this step were to clearly identify and discuss these differences and to determine the relative significance of the tradeoffs among concepts. These comparisons were made by sequentially examining each pair of top-ranked concepts. Committee members discussed in depth the significance of each tradeoff and selected the most preferred concept of each pair. Then, on the basis of the discussions and pairwise comparison results, the committee developed a final preference ordering of concepts and the associated rationale to document the results. Section 6.0 contains the results of the pairwise comparison step.

\subsubsection{Step 7: Recommend Two Preferred Concepts}

The first and second concepts, respectively, in the final preference ordering from step 6 were chosen as the two preferred concepts. This result is documented in Section 7.0 . 


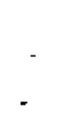




\subsection{NORMAL IZATION OF CANDIDATE MRS CONCEPTS}

Numerous concepts for the storage of spent fuel and solidified high-level waste/transuranic waste have been studied during the past 15 to 20 years. Unfortunately, the results of these studies are difficult to compare due to inconsistent assumptions for throughput rates, storage capacities, and projected facility lifetimes. To assure an equitable comparison of the candidate storage concepts in the concept selection process, conceptual design analyses were performed for the candidate concepts by contractors with previous experience in MRS concept designs. Each conceptual design met specified functional performance criteria and system requirements. These requirements were chosen to reflect the current understanding of the mission of an MRS facility.

The candidate storage concepts are introduced in Section 3.1. The functional criteria and system requirements are presented in Section 3.2. The common interface between the storage arrays and the rest of the waste management system (the Receiving and Handling facility) is described in Section 3.3, and the key information related to each of the storage concepts is presented in Section 3.4 .

\subsection{CANDIDATE MRS CONCEPTS}

Concepts for the storage of spent fuel and/or HLW/TRU have been studied for many years. The best-known concept, water pools, requires active cleanup and cooling systems and, therefore, does not satisfy the criteria for a cooling system that is independent of power sources and active equipment.

In 1979, Congress directed the Department of Energy to study the feasibility of long-term storage of spent fuel and/or solidified HLW/TRU, a directive which resulted in the publication of DOE/NE-0019, The Monitored Retrievable Storage Concept--A Review of Its Status and Analysis of Its Impact on the Waste Management System, and PNL-4450, Comparison of Cask and Drywell Storage Concepts for a Monitored Retrievable Storage/Interim Storage System. In these studies, the considerations were limited to dry, passively cooled systems. 
In 1983, following the passage of the Nuclear Waste Policy Act of 1982, an MRS Research and Development Needs Report to Congress was prepared that identified eight leading candidate concepts for design of an MRS facility. These candidate concepts, listed below, are all dry and passively cooled, thereby satisfying the criteria for passive cooling systems.

- Metal cask (stationary and transportable)(a)

- Field drywell

- Concrete cask (silo)

- Concrete cask-in-trench

- Open cycle vault

- Tunnel drywe11

- Closed cycle vault

- Tunnel rack vault

\subsection{FUNCTIONAL CRITERIA AND SYSTEM REQUIREMENTS}

A common set of functional criteria and system requirements was utilized in the analyses of the candidate MRS concepts. The actual design requirements used in the development of the proposal to Congress may differ somewhat from those used for concept comparison purposes (listed below), since the latter were specified early in the program.

- Licensable by the NRC (20 year license, renewable)

- 40-year design lifetime (maintainable or replaceable to double lifetime)

- Initial operation in 1998

- Design capacity of 15,000 MTU spent fuel, or equivalent in HLW/TRU (expandable to 72,000 MTU)

- Waste acceptance rate of 1,800 MTU/year (expandable to 3,000 MTU/year)

- Waste discharge rate of 1,800 MTU/year (expandable to 3,000 MTU/year)

- Capable of safe storage or disposal of all wastes generated at the facility while handling spent fuel or solidified HLW/TRU

(a) Since they differ in their operational characteristics, the two operational variations of the metal cask (stationary and transportable) were considered separately in this evaluation. 
- Capable of storing fuel elements up to 14 feet 9 inches long, with 9 -inch square cross-sections

- Capable of handling canisters of HLW 10 feet long and 1 foot in diameter

- Capable of maintaining spent fuel cladding temperatures below 400 degrees $C$ in an inert gas, assuming heat generation rates of 550 watts for a PWR element that contains $462 \mathrm{~kg}$ of initial $\mathrm{U}$ and 175 watts for a BWR element that contains $186 \mathrm{~kg}$ of initial $\mathrm{U}$

- Capable of maintaining HLW container surface temperature below 375 degrees $C$, assuming a heat generation rate of 2,000 watts per 12-inch diameter canister.

In addition to these specific requirements, a set of general assumptions was adopted as a guide for the design of the facility. A listing of these assumptions is given below:

- The MRS system shall have the capability to receive, inspect, repackage as necessary, store, and retrieve the stored material for subsequent shipment.

- The MRS system shall be capable of containing radioactive material within the storage unit during the entire storage period.

- The MRS system shall have a monitoring system capable of detecting any releases of radioactive material.

- The MRS system shall be capable of protecting the stored material against any likely natural or man-created events, excluding acts of war.

- The MRS system shall be capable of passively removing the heat generated from decay of radioactive materials that have been discharged from a reactor for at least 10 years.

- The MRS system shall be capable of adequately protecting operating personnel and the public from the radiation emitted from the stored material. 
- The MRS systern shall be capable of interacting with all systems within the total waste management system, including the reprocessing and disposal systems.

- The MRS system shall be capable of accounting for the quantity, type, and history of the material stored in the facility.

- Security, surveillance, and physical protection shall be provided for the facility, with additional safeguards provided to vital areas, in accordance with federal regulations.

- The MRS facility shall be designed to preclude any nuclear criticality events.

- The MRS facility shall be modular in design and capable of incrementally increasing or decreasing its processing rate and storage capacity to accommodate different circumstances.

- A generic Receiving and Handling facility is specified to be used in all concept evaluations (except the transportable metal cask).

\subsection{GENERIC RECEIVING AND HANDLING FACILITY}

An important consideration in the design of an MRS facility and in the selection of appropriate storage concepts is that the MRS system should not constrain the operation of the rest of the waste management system. Rather, the MRS system should be an integrated component of the total system and should readily accommodate the operational requirements of at-reactor storage, transportation, and the repositories. In recognition of this need, a common interface with the rest of the waste management system was provided so that interactions with transportation and at-reactor storage and handling components were common across all storage concepts. This interface, the Receiving and Handling $(R \& H)$ facility and its supporting structures, provided the transition from the transport devices (truck and/or rail casks) to the storage devices, and assured that none of the concept comparisons were unfairly biased by having different interface systems. 
A conceptual design for the generic R\&H facility was developed by Raymond Kaiser Engineers, based on their previous design efforts related to the Basalt Waste Isolation Project (BWIP), and is reported in KEH R-83-96, MRS Conceptual System Study: Dry Receiving and Handling Facility. The R\&H building and supporting structures are a significant portion of the total MRS facility and are generic to all of the storage concepts considered (except for the transportable metal cask, which incorporated an R\&H building that was much reduced in its scope of activities). The full-sized facility encompasses an area of about 64 acres and includes the R\&H building as the principal structure, as well as a number of supporting structures. The R\&H building is about $430 \mathrm{ft} \times 320 \mathrm{ft}$ in an irregular rectangular dimension, covers about 100,000 square feet of area on the ground ievel, rises about 60 feet above grade level, and includes one major stack that extends well above the top of the structure.

The R\&H facility is designed to receive spent fuel and HLW in shieided rail or truck casks, unload the casks, do all necessary inspections, consolidate spent fuel into sealed metal canisters, and transfer the canistered spent fuel or waste to the storage area. The R\&H facility can also process canisters retrieved from storage and load them into casks for shipment. Suspect canisters can be inspected, repaired or replaced as needed, and returned to storage or shipped. Radiation monitoring will be conducted both inside and outside the R\&H building and in the storage areas to ensure that radiation levels on or about the facility or area do not exceed preset limits.

\subsection{INFORMATION ON STORAGE CONCEPTS}

As mentioned earlier in this section, conceptual design analyses of candidate storage concepts were performed by contractors who had extensive previous experience in the development and evaluation of concepts for storage of radioactive materials. To the extent possible, the firms were assigned concepts for evaluation that were most closely related to their past experience, to take maximum advantage of that knowledge base. The concept assignments were as follows: 
- Boeing Engineering Company (concrete cask, cask-in-trench, open cycle vault)

- GA Technologies, Inc. (closed cycle vault, tunnel rack vault)

- Westinghouse Electric Corporation (metal cask, field dryweli, tunnel drywe11)

For each of the storage concepts, a report was prepared that presented the results of the evaluation of that concept for the set of functional criteria and system requirements given previously in Section 3.2. Brief descriptions of each storage concept, together with some of the key items of information from the corresponding concept evaluation report, are given in the following subsections.

\subsubsection{Metal Storage Cask (stationary)}

The concept evaluation report for the stationary metal storage cask is WTSD-TME-010, MRS Conceptual System Study; Metal Storage Cask. A metal storage cask MRS facility utilizes large metal casks, illustrated in Figure 3.1, for the storage of canisters of spent fuel or solidified HLW/TRU. The facility consists of five principal components in addition to the generic Receiving and Handling facility:

1. Large metal casks into which the spent fuel or reprocessing wastes are placed for storage. The cask has sufficient shielding (steel, lead, water) to keep the radiation levels at the exterior of the loaded cask at acceptable values, and has heat transfer capabilities adequate to keep the temperatures in the stored radioactive materials at acceptable levels. Double seals provide redundant containment of the canistered material within the cask.

2. An onsite transporter to carry the loaded storage casks from the R\&H facility to the storage area and to return the casks to the $R \& H$ facility when retrieval is initiated.

3. A suitable foundation (such as a reinforced concrete pad) for storage of arrays of casks. 

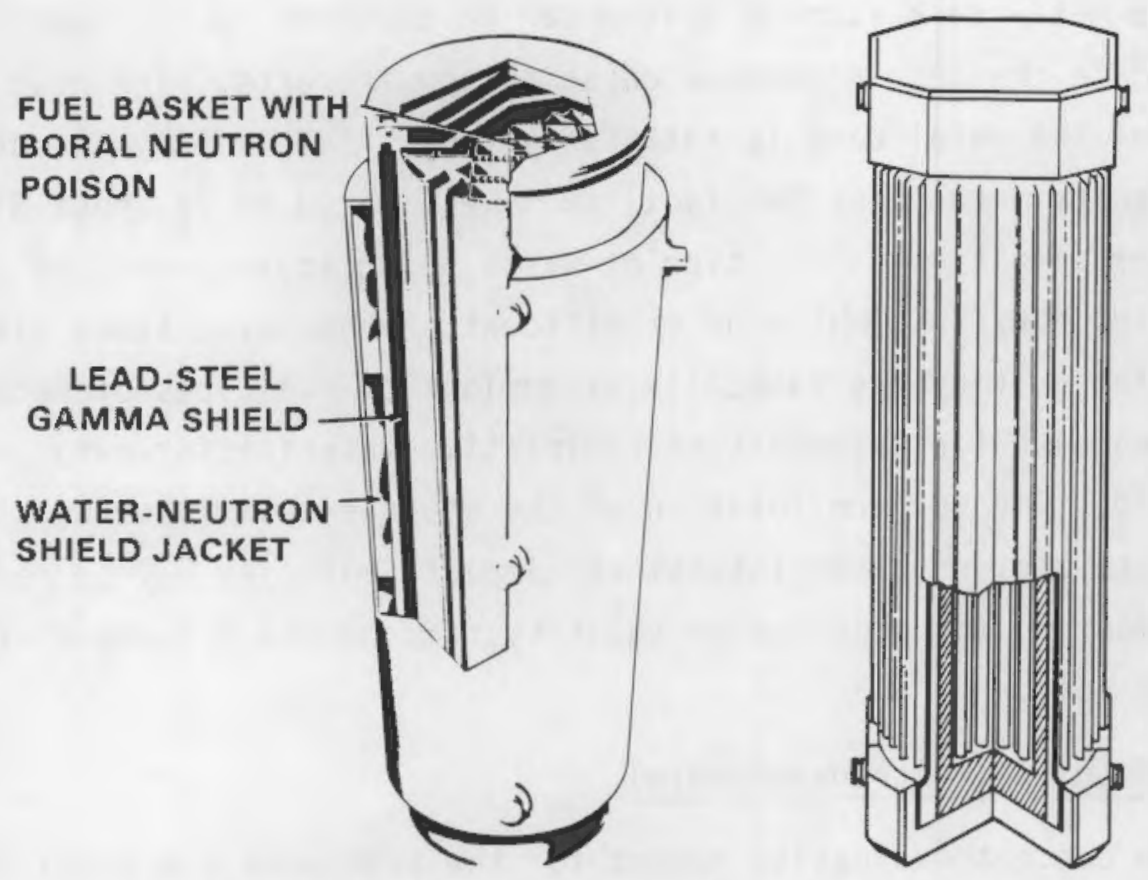

FIGURE 3.1. Metal Storage Cask Concept

4. A mobile straddle crane to remove the loaded cask from the transporter, place it on the storage pad, and transfer it from the pad to the transporter for retrieval.

5. A system for monitoring the integrity of the cask seals and for detecting releases of radioactive material from the stored canisters to permit correction before release from the cask can occur. Area monitoring is also provided to monitor site conditions outside of the casks.

A typical metal cask is about $2.5 \mathrm{~m}$ in diameter and $5 \mathrm{~m}$ in height, and weighs somewhat under 100 tonnes. Heat from the radioactive decay of the stored material is conducted through the metal cask wall and transferred to the atmosphere by surface convection and thermal radiation.

The casks are stored in a secured, fenced area to minimize intrusion. Depending upon the climate at the site, the storage area could be in the open or could be enclosed within simple structures. 
The metal cask storage system can be expanded in increments of one cask to accommodate changes in storage capacity requirements. The heat removal capability of the metal cask is relatively good. The life-cycle cost for a 15,000 MTU capacity metal cask MRS facility is estimated to be about $\$ 1.3$ billion, but is rather sensitive to the type of waste being stored, whether spent fuel or solidified HLW/TRU. While no significant storage experience with metal casks is available, they are basically extensions of the types of metal casks that have been used for transport of radioactive material for many years all over the world. The surface location of the storage casks increases their vulnerability to accidental or intentional impact, but they may be perceived to be more temporary than the larger vault systems or the systems that are embedded into the soil.

\subsubsection{Metal Cask (transportable)}

The concept evaluation report for the transportable metal storage cask is WTSD-TME-013, MRS Conceptual System Study: Transportable Metal Cask. The transportable metal cask can be envisioned as simply the stationary metal cask, with the addition of appropriate overpacks and impact limiters as required to license a fully-loaded cask for transport. The cask is received at the MRS site on a railcar and is placed on a transporter for delivery to the storage pad, where it is positioned using a crane. Removal from storage is just the reverse of these steps. This study did not consider truck-transportable storage casks, which should be similar to the rail casks, but less economical.

The transportable metal cask can ship and store unconsolidated spent fuel, either canistered or uncanistered, canistered consolidated spent fuel, and canistered high-level waste. The R\&H facility is much reduced in size and scope from that needed for other concepts, since it is needed only for the decontamination and repair of an occasional leaking canister, as well as routine receiving/handling, inspection, and washdown of the incoming casks. No consolidation capability was provided in the case studied, since spent fuel will be stored in its as-received condition. Note that the transportable metal cask was evaluated in this study only for its potential use in an MRS facility. It was not evaluated for use as an at-reactor storage option. 
The life-cycle cost for a 15,000 MTU capacity transportable metal cask MRS facility is estimated to be about $\$ 1.1$ billion, with the lower cost relative to the stationary cask concept resulting from a much-reduced Receiving and Handling facility. In all other aspects, the transportable storage cask is the same as the stationary storage cask.

\subsubsection{Concrete Cask}

The concept evaluation report for the concrete cask is BEC-MRS-8302, MRS Conceptual System Study: Concrete Storage Cask. A concrete cask MRS facility utilizes large cylinders of reinforced concrete, illustrated in Figure 3.2, for the storage of canisters of spent fuel or solidified HLW/TRU. The facility consists of five principal components in addition to the generic Receiving and Handling facility:

1. Large reinforced concrete casks for storage of the canistered spent fuel and/or solidified reprocessing waste, with sufficient shielding to reduce the radiation dose rate at the cask surface to an acceptable level, and with heat removal capacity adequate to keep the temperatures of the stored waste at acceptable levels. Seals on the cask cavity provide redundant containment of the radioactive material stored in the sealed canisters within each cask.

2. An onsite transporter to carry the loaded storage cask from the Receiving and Handling facility to the storage area, and to return the cask to the Receiving and Handling facility when retrieval is necess ary.

3. A suitable foundation (storage pad) for storage of arrays of casks.

4. A mobile crane to transfer the loaded cask from the transporter to a storage pad, and to transfer the cask from the pad to the transporter when retrieval is initiated.

5. A system for detecting releases of radioactive material from the stored canisters to permit correction before a release from the cask can occur. Area monitoring is also provided to monitor site conditions outside of the cask. 


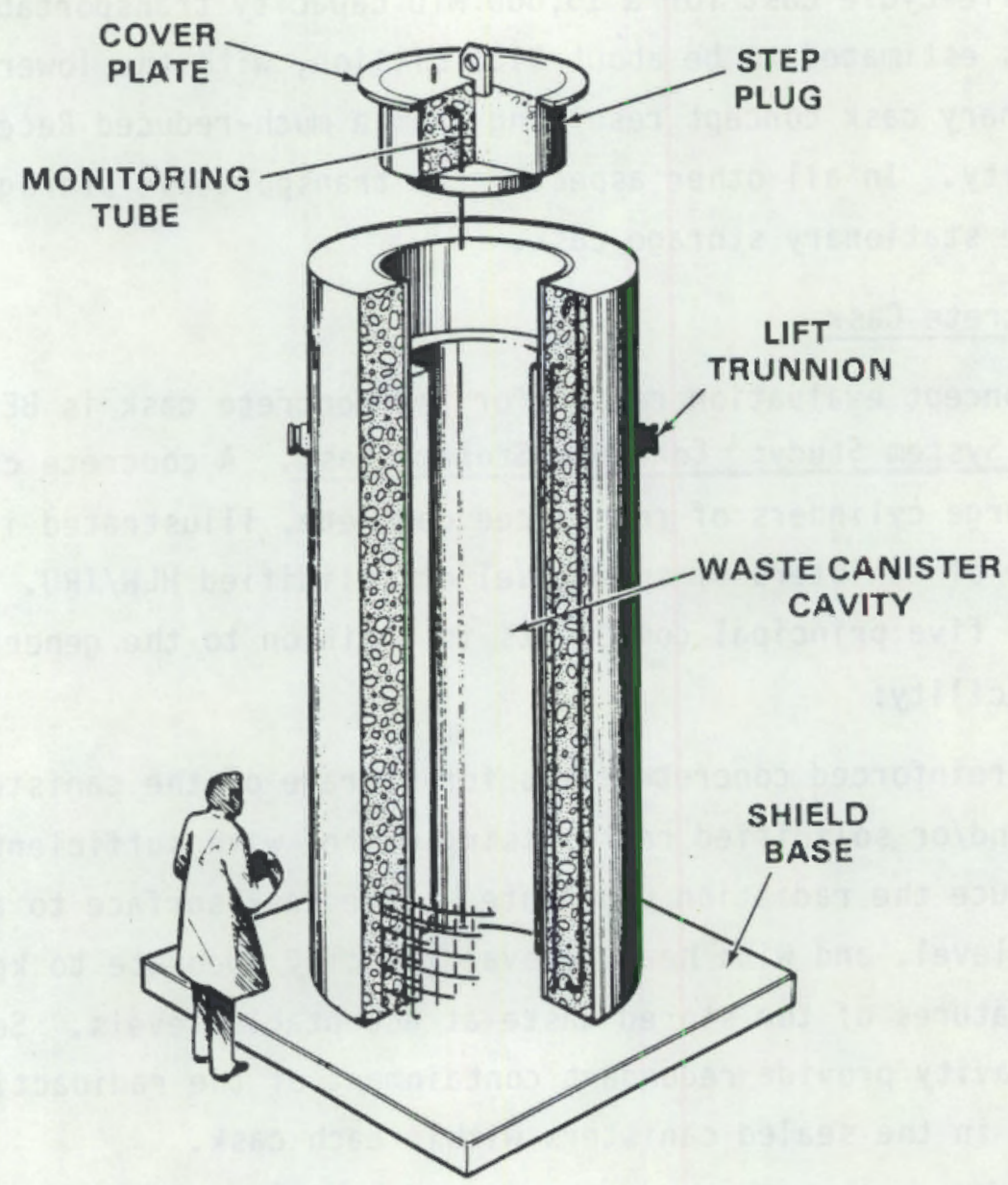

FIGURE 3.2. Concrete Cask Concept

A typical concrete cask is about $3 \mathrm{~m}$ in diameter and $6 \mathrm{~m}$ in height, and weighs about 100 tonnes. Heat from the radioactive decay of the stored material is conducted through the concrete and transferred to the atmosphere by surface convection and thermal radiation. The reinforced concrete structure, combined with the sealed waste canister, is designed to withstand credible man-caused and natural events. The storage arrays are enclosed within a secured fenced area to minimize intrusion.

The concrete cask storage system can easily be expanded in small increments to accommodate changes in capacity requirements. The concrete cask can be designed to accommodate relatively large heat loads. The life-cycle cost for a 15,000 MTU capacity concrete cask storage MRS facility is estimated to be 
about $\$ 820$ million, and is relatively insensitive to whether the waste being stored is spent fuel or solidified HLW/TRU. The concrete cask is a relatively mature concept, with several years of research and development work and actual storage operations, both in the U.S. and in Canada. Since the concrete cask stands on the surface, it is more exposed to accidental or intentional impacts, but may be perceived as being less permanent than a subsurface storage device.

\subsubsection{Cask-In-Trench}

The concept evaluation report for the cask-in-trench is BEC-MRS-8303, MRS Conceptual System Study: Cask-In-Trench. The cask-in-trench concept is a variation of the concrete storage cask. A cask similar in configuration to the concrete storage cask is placed in a trench (or berm) that is subsequently backfilled to be level with the top surface of the cask. In most other respects, the cask-in-trench is the same as the concrete storage cask.

The cask-in-trench storage system can easily be expanded in small increments to accommodate changes in the capacity requirement. Since the cask is embedded in the soil, its heat removal capability is less than that of the surface cask. The life-cycle cost for a 15,000 MTU capacity cask-in-trench MRS facility is estimated to be about $\$ 1.5$ billion, and is relatively insensitive to the type of waste stored, whether spent fuel or solidified reprocessing waste.

The cask-in-trench is an untried concept, but its characteristics are sufficiently similar to the concrete surface cask and the field drywell to be amenable to computational analysis. Since the cask-in-trench is embedded into the soil, it is more protected against accidental or intentional impacts, but may be perceived as being more permanent that the surface storage devices. Retrieval from storage requires excavation of the soil from around the embedded cask, thus making retrieval somewhat more difficult than for other storage concepts.

\subsubsection{Field Drywell}

The concept evaluation report for the field drywell is WTSD-TME-011, MRS Conceptual System Study: Open field Drywell. A field drywell MRS facility, illustrated in Figure 3.3, utilizes stationary, in-ground, dry, sealed 


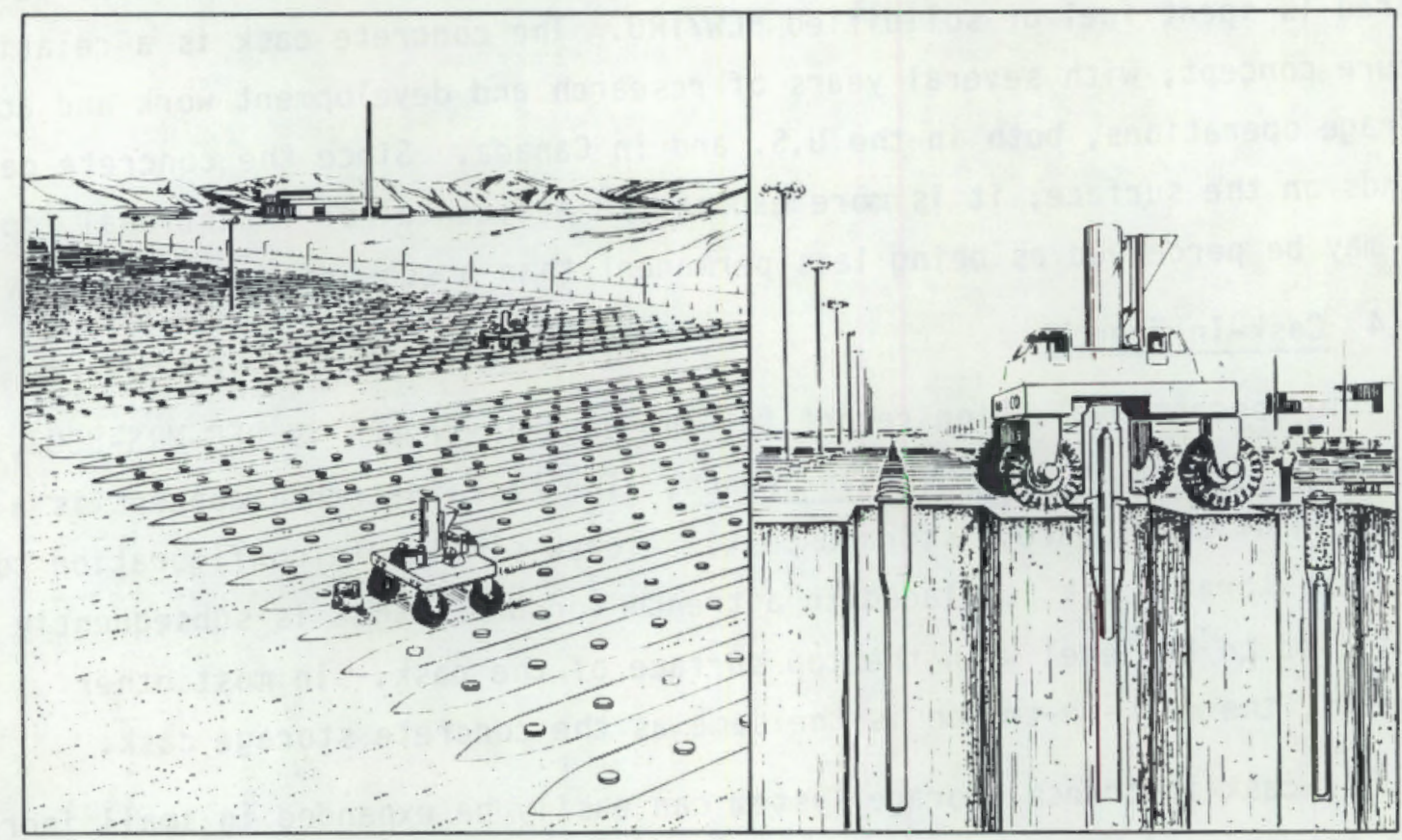

FIGURE 3.3. Field Drywell Concept

containers (drywells) for storage of spent fuel or reprocessing waste. The facility consists of three major components in addition to the generic R\&H facility:

1. An array of near-surface drywells in a field into which the canisters of radioactive material are placed for storage and from which the canisters can be retrieved for final disposition. The drywells are sealed after loading, providing a redundant barrier between any leakage from the canisters and the environment.

2. An onsite transporter containing a shielded transfer cask to carry the canisters of radioactive material from the R\&H facility and insert them into the proper drywell location in the field, and later retrieve them from their storage locations and return them to the R\&H facility.

3. A system for detecting releases of radioactive material from the stored canisters in the drywells to permit correction before a 
release from the drywell could occur. Area monitoring is also provided to monitor site conditions.

A typical drywell is about $1 / 2 \mathrm{~m}$ in diameter and extends approximately 8 meters into the ground. The surrounding soil serves to attenuate any emitted radiation and to transfer the decay heat from the stored materials to the atmosphere. Drywells may be inserted into the existing soil at a site, or an engineered berm may be built to ensure consistent soil characteristics and further reduce the chance of water intrusion. The arrays of drywells are enclosed within a secured fenced area to minimize intrusion.

The field drywell storage array can easily be expanded in small increments, to accommodate changes in capacity requirements. The life-cycle cost for a 15,000 MTU capacity field drywell MRS facility is estimated to be about $\$ 650$ million, and is relatively insensitive to whether the waste being stored is spent fuel or solidified reprocessing waste. The drywell is a relatively mature concept, with a number of years of research and development and a considerable history of actual storage operations at several DOE sites. Since the drywell is inserted into the soil, it is protected from accidental or intentional impacts, but may be perceived as being more permanent than the surface storage devices.

\subsubsection{Tunnel Drywell}

The concept evaluation report for the tunnel drywell is WTSD-TME-012, MRS Conceptual System Study: Tunnel Drywell. A tunnel drywell MRS facility, illustrated in Figure 3.4, utilizes underground storage of canisters of spent fuel or reprocessing waste in drywells located within a mined tunnel. This facility consists of the same major components as the field drywell. The spent fuel or reprocessing waste is sealed in canisters and is placed by a shielded transporter in drywells set in the floors of tunnels. The drywell is sealed after loading to provide redundant containment. The surrounding rock is used to attenuate nuclear radiation emitted and to dissipate the decay heat.

The life-cycle cost for a 15,000 MTU capacity tunnel drywell MRS facility is estimated to be about $\$ 1.2$ billion and is relatively insensitive to the type of waste being stored, whether spent fuel or solidified reprocessing waste. 


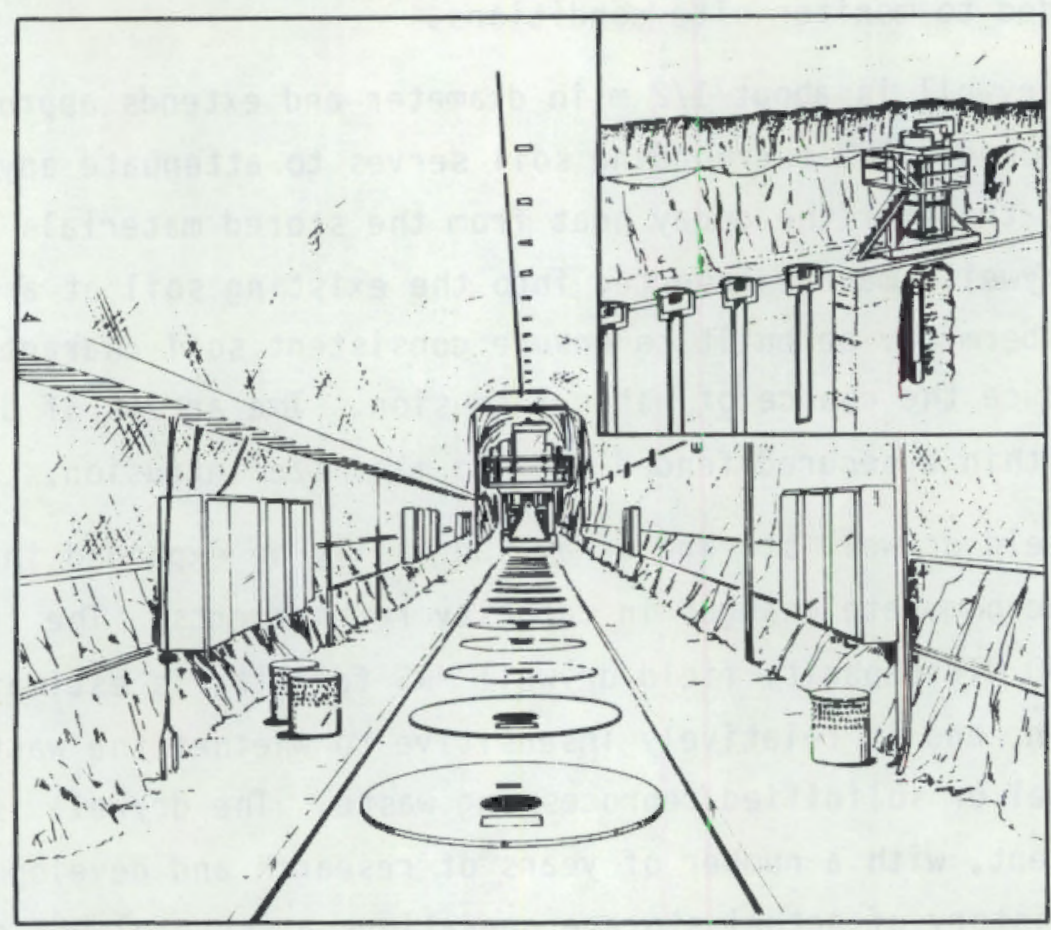

FIGURE 3.4. Tunnel Drywell Concept

The tunnel drywell has had several years of research and development demonstration at a DOE site. Since the drywells are contained within tunnels, they are well-protected against accidental or intentional impact, but may be perceived to be a "permanent" rather than "temporary" storage system.

\subsubsection{Open Cycle Vault}

The concept evaluation report for the open cycle vault is BEC-MRS-8304, MRS Conceptual System Study: Open Cycle Vault. An open cycle vault MRS facility, illustrated in Figure 3.5, utilizes a large shielded warehouse for storage of canisters of spent fuel or reprocessing waste. The facility consists of four major components in addition to the generic Receiving and Handling facility:

1. A large building with thick concrete shielding to house the canisters of spent fuel or solidified reprocessing waste. The storage area can be above or below ground level. Large-volume ventilation stacks will extend above the top of the building. 


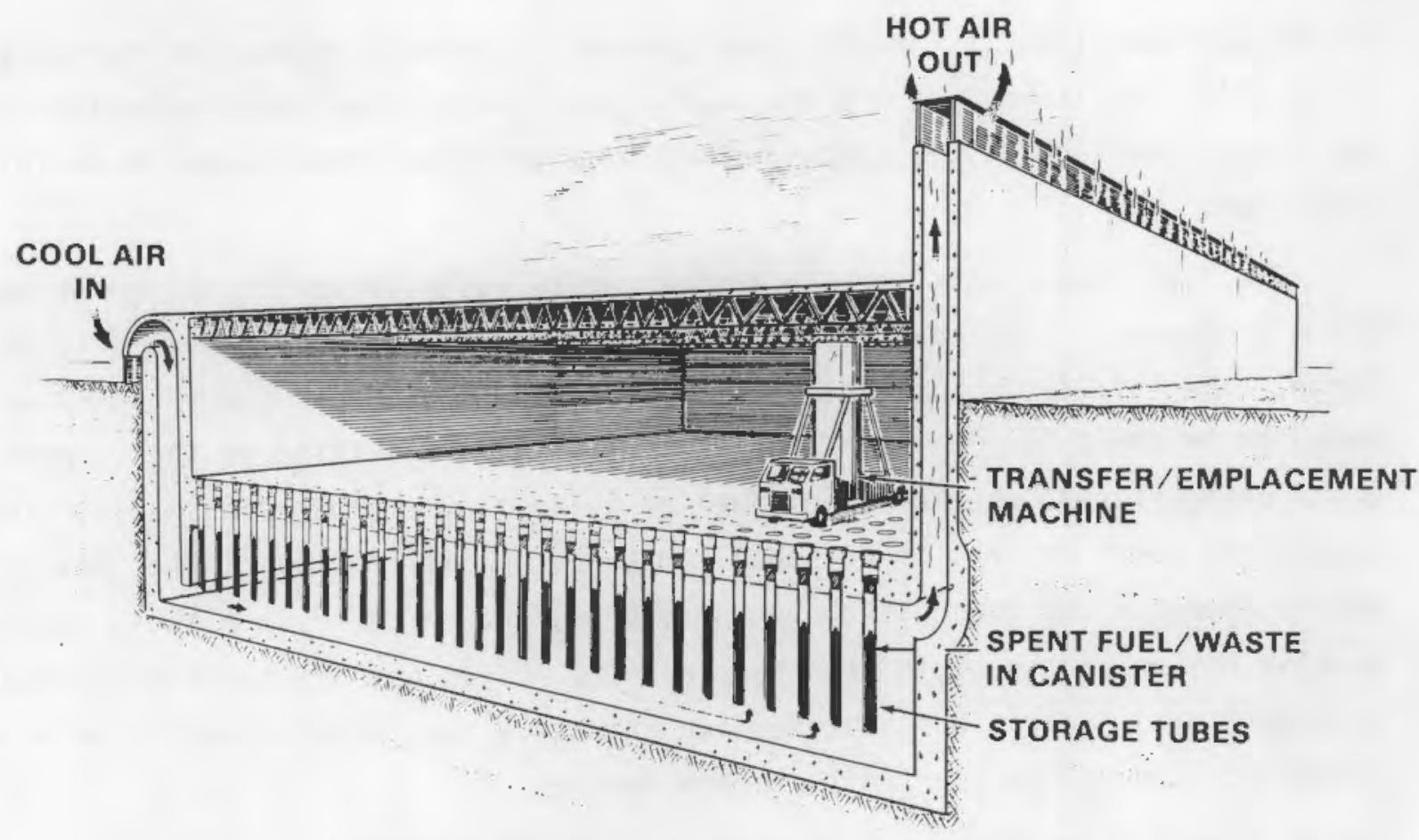

FIGURE 3.5. Open Cycle Vault Concept

2. A crane or other mechanical transporter to move the canistered radioactive material into its storage location, and to place any additional covers that may be required over the canisters. The same system is used to retrieve the canisters from storage. The canisters are placed vertically in the storage tubes, which keep the canisters rigidly positioned 0.3 to 1 meters apart. The storage tubes are sealed after loading, providing a redundant barrier between any leakage from the sealed canisters to the environment.

3. A system of air ducts directing and distributing outside air past the storage tubes for cooling, with discharge of the air to the atmosphere. The large volume of air flow requires no blowers; it is induced by the natural draft caused when the heat from the containers is transferred to the air.

4. A system for monitoring the air in the interior of the storage tubes and the air flow through the vault, to detect any leakage of radioactive material from the canisters to permit correction before a release to the environment can occur. 
In the open cycle vault concept, the barriers to prevent release of radioactive material to the atmosphere are the sealed storage canister and the sealed storage tube. The facility is contained within a secured, fenced area to minimize intrusion.

The open cycle vault storage system can be expanded in increments of about 500 MTU capacity. The heat removal capability of the open cycle vault is quite large. The life-cycle cost for a 15,000 MTU capacity open cycle vault is estimated to be about $\$ 1.0$ billion, and is relatively insensitive to the type of waste being stored, whether spent fuel or solidified reprocessing waste. The open cycle vault concept is reasonably mature. Facilities of similar design are in operation in the United Kingdom (Wyfla) and in the U.S. (INEL). The massive nature of the vault structure reduces its vulnerability to accidental or intentional impact, but that massive structure may be perceived to be more permanent than the smaller unit storage devices.

\subsection{8 closed Cycle Vault}

The concept evaluation report for the closed cycle vault is GA-A17322, MRS Conceptual System Study: Closed Cycle Vault. A closed cycle vault MRS faci1ity utilizes a large shielded enclosure for storage of the spent fuel or reprocessing wastes and employs natural circulation of air to remove the decay heat from the stored material. Closed cycle vaults differ from open cycle vaults in that the decay heat is transferred from the stored material through an overpack to natural convection cooling ducts in the concrete and then through heat pipes from the cooling ducts to the outside air.

Several different closed cycle vault designs have been proposed for dry storage of spent fuel and solidified reprocessing waste. A specific module of a closed cycle vault MRS facility is illustrated in Figure 3.6. The facility evaluated consists of five principal components in addition to the generic R\&H facility:

1. Multiple concrete storage modules, each containing nine locations for storage of radioactive material.

2. Large sealed overpack containers that can accommodate multiple spent fuel or waste canisters. 


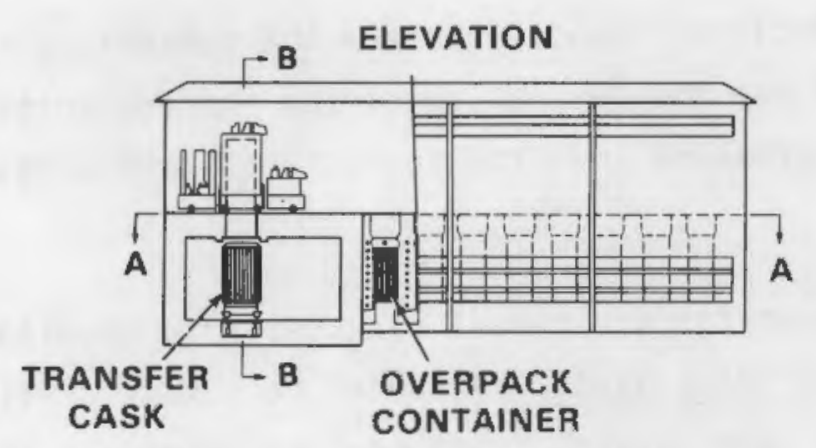

SECTION B-B

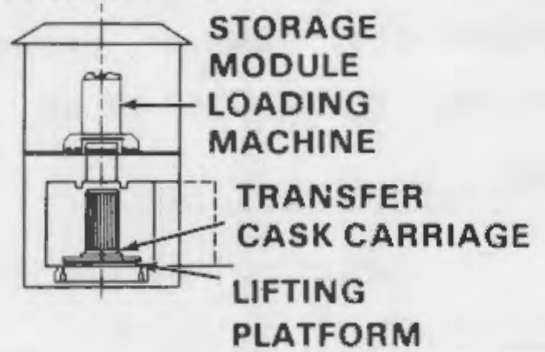

SECTION A-A

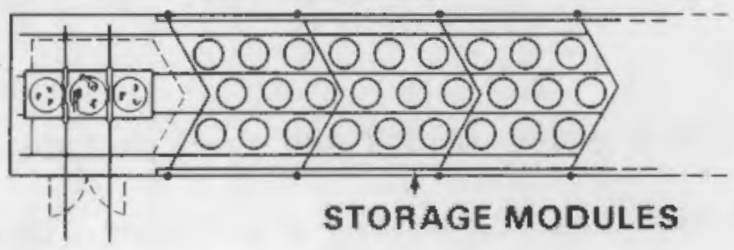

FIGURE 3.6. Closed Cycle Vault Concept

3. A transfer cask for transporting the loaded overpack container from the R\&H facility to the storage module loading machine.

4. A storage modular loading machine that transports the overpack container to the storage location, inserts it into the storage module, and then retrieves it when necessary.

5. A system for detecting releases of radioactive material from the stored canisters to permit correction before a release to the environment could occur.

In the closed cycle vault concept, the barriers designed to prevent release of radioactive material to the atmosphere are the spent fuel or waste canister and the overpack container. The storage arrays are contained within a secured, fenced area to minimize intrusion. The closed cycle vauit storage system can be expanded in increments of about 100 MTU capacity. The life-cycle cost for a 15,000 MTU capacity closed cycle vault is estimated to be about $\$ 950$ million. The fixed geometry of the overpack container makes this concept rather sensitive to the type of waste being stored, whether spent fuel or solidified reprocessing waste. The heat removal capability of the closed cycle vault has not been demonstrated, but the design is based on well-developed heat-pipe technology. Since the storage modules stand on the surface, they are 
more exposed to accidental or intentional impact than are the subsurface storage concepts. However, because of the modular nature of the storage units, they may be perceived to be less permanent than the subsurface storage devices.

\subsubsection{Tunnel Rack Vault}

The conceptual evaluation report for the tunnel rack vault is GA-A17323, MRS Conceptual System Study: Tunnel Rack Vault. A tunnel rack vault, illustrated in Figure 3.7, utilizes the same natural draft cooling principle as the open cycle vault. The facility consists of five principal components in addition to the generic R\&H facility:

1. Canister storage racks, which are unshielded and transportable.

2. Remotely-operated transfer machines for moving the loaded storage racks from the $\mathrm{R} \& \mathrm{H}$ facility into the storage tunnels. The same machines are used to return the racks to the R\&H facility for unloading.

3. Storage tunnels, which are accessed from a main transfer tunnel. Preferred orientation is with the R\&H facility on the surface and the storage facility at the same elevation under a nearby hill.

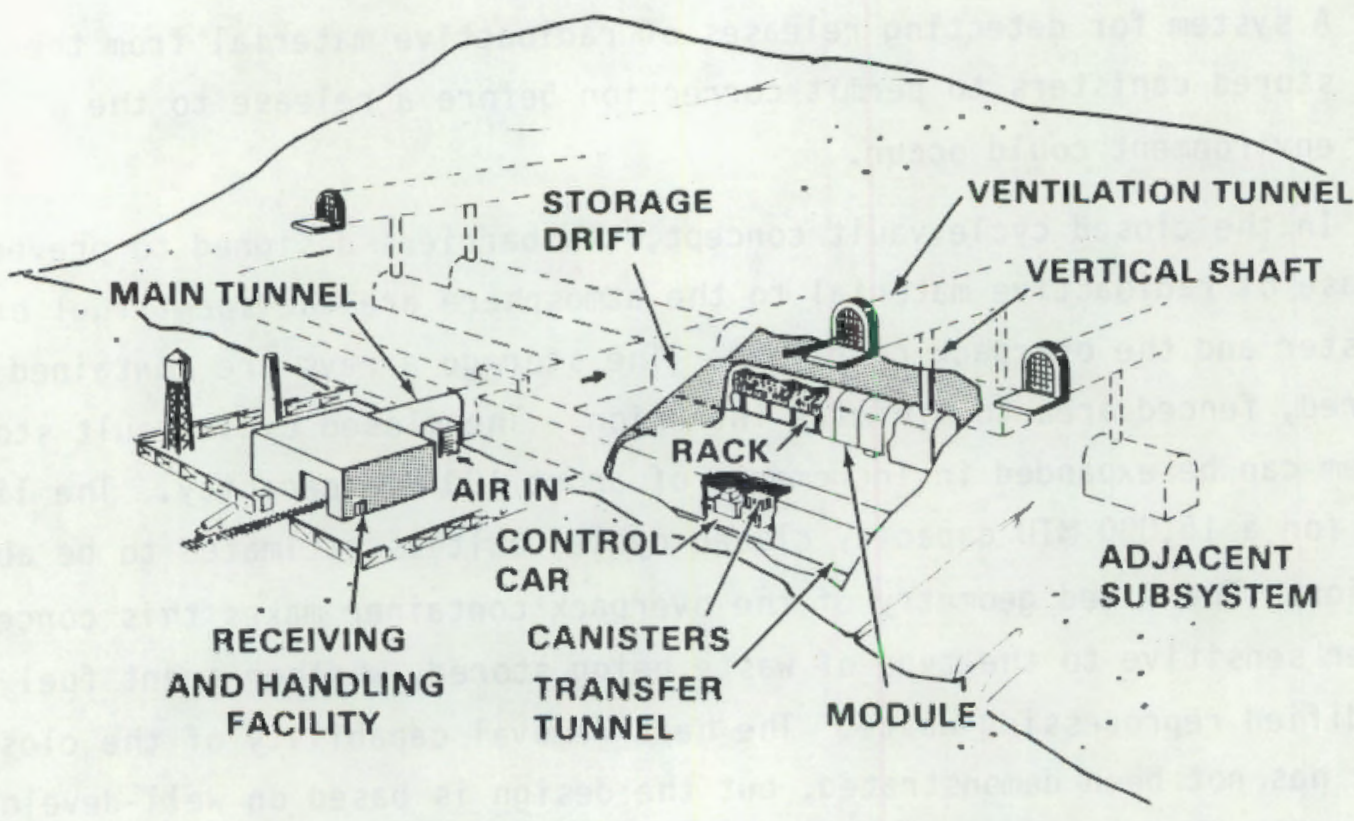

FIGURE 3.7. Tunnel Rack Concept 
4. Ventilation tunnels providing air passages for the natural convective cooling of the stored material.

5. A system for continuous monitoring of cooling air to detect leakage of radioactive material from the stored canisters, and a visual monitoring system using remotely controlled television cameras. Area monitoring is also provided to monitor site conditions.

The facility is enclosed within a secured, fenced area to minimize intrusion.

In the tunnel rack vault concept, the spent fuel or reprocessing waste canisters form the final barrier to the release of radioactive material into the atmosphere. The location of the storage arrays within tunnels makes securing the storage areas against accidental or intentional public intrusion relatively easy. The life-cycle cost for a 15,000 MTU capacity tunnel rack vault is estimated to be about $\$ 850 \mathrm{million}$, and is relatively insensitive to the type of waste being stored, whether spent fuel or reprocessing waste. The tunnel rack vault is an undemonstrated concept, but has many characteristics similar to the open cycle vault. Since the storage units are located within tunnels, they are well protected against accidental or intentional impact but may be perceived as being "permanent" rather than "temporary" storage. 



\subsection{RANKING RESULTS BY CRITERION}

Separate evaluations of the nine candidate concepts were conducted for each of the seven criteria. The results of these evaluations are described in this section. The relative merits of the concepts are described for each of the descriptors that comprise a criteria. Finally, an ordinal ranking of concepts is presented for each criterion along with the rationale for the ranking.

\subsection{SAFETY/LICENSING CRITERION}

The safety/licensing criterion is concerned with the characteristics of MRS concepts with respect to their performance in the following areas: risk of excessive radiation exposure to the public, occupational safety of the operating staff, and the licensability of the facility. Many aspects of the safety characteristics are related to each other.

It is presumed that there are no fundamental problems which would prevent the candidate MRS concepts from meeting licensing requirements. Therefore, the concepts are compared on the basis of which possess the greatest inherent safety and licensability, or could be most easily made so. Overall performance of the candidate concepts on safety/licensing was determined by considering the relative merits of each concept for each of the following nine descriptors:

- ease of conformance with licensing requirements

- criticality safety

- Inonitorability

- containment integrity

- accident/malfunction recoverability

- design testing

- penetrability and security

- accountability

- previous licensing experience.

The principal differences between storage concepts relative to each of these descriptors are discussed in succeeding sections. These discussions are followed by a listing of the ordinal ranking for the concepts under the safety/ licensing criterion, and the rationale for that ranking. 


\subsubsection{Ease of Conformance with Licensing Requirements}

This descriptor characterizes the inherent ability of an MRS concept to satisfy the major licensing requirements perceived to apply to such a facility. Licensing is anticipated to be done under the provisions of 10 CFR 72 when revised to accommodate high-level waste storage. Much of this regulation will impact all concepts equally, in such issues as siting, training, etc. However, issues related to the preparation of an acceptable safety analysis report (SAR) are perceived to vary significantly among concepts. The principal issues here are system complexity, data from testing and operation, the effects of equipment failure, ventilation methods, the susceptibility to accidents, the effectiveness of the cooling system, and the safety margins to accommodate performance uncertainties. In addition, the ability of the concept to satisfy the

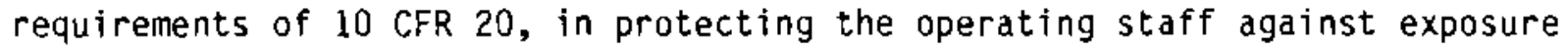
to radiation, is an important consideration.

Those concepts that are least complex are the easiest to analyze for compliance with safety/licensing requirements. The fewer systems that need to function, the fewer will be the system-disabling failures. Those concepts that require a significant amount of remote-handling operations in the storage area will be the ones most difficult to return to service following an equipment malfunction or failure.

Demonstrated proof of performance is very valuable in the development of an SAR. Those concepts that have been built and tested can more easily show compliance with safety/licensing requirements than concepts that have never been demonstrated.

Some concepts require more contact-handling time for the emplacement or retrieval of the wastes than do other concepts, thus causing greater exposure of the operating staff to radiation. Similarly, the ease or difficulty of decontaminating the storage units following a release of radioactive material from a storage canister will affect the radiation exposure to the operating staff. 


\subsubsection{Criticality Safety}

All of the candidate concepts can be designed to minimize the potential for a nuclear criticality event. However, there are differences in the ease of assuring criticality safety in the event of certain natural phenomena, such as earthquakes, tornados, or floods.

Nuclear criticality depends on the amount of spent fuel present, its chemical and isotopic form, its physical configuration and the amount of water present. Natural phenomena can damage the storage system and affect the latter two items.

Below-ground storage units are more susceptible to flooding. Above-ground units are more susceptible to changes in physical configuration due to tornados, for example.

\subsubsection{Monitorability}

The degree to which the candidate concept facilitates the detection and location of leaking canisters is an important factor. Also, important is the degree to which the concept facilitates the visual inspection of the storage units, and the measurement of any releases of radioactivity that could affect the operating staff or the offsite population.

Concepts that have double containment of the stored material are most adaptable to detection of leakage from a canister before that leakage is released to the environment.

The ability to detect and locate a leaking canister so that it can be retrieved for repair varies among concepts. Those concepts that store one or a few canisters in a closed, sealed environment (casks, drywells, closed cycle vault) can best satisfy this need. A concept that employs a small air flow past single canisters can reasonably detect significant leaks. A concept that has a large volume of air flowing directly past the stored canisters (tunnel rack vault) has the greatest difficulty in satisfying this need.

It is anticipated that there would be no difference in the ability of the candidate concepts to detect and measure any releases of radioactivity at the boundary of the MRS site. 
Visual inspection of the storage units is necessary to facilitate accountability. Direct observation of the canisters while in storage could be accomplished only in the tunnel rack vault.

\subsubsection{Containment Integrity}

The probability of radioactive release from an MRS facility must be acceptably small, from both internal and external events. Although all of the candidate concepts must meet licensing requirements with respect to postulated tornados, earthquakes, other natural phenomena, and postulated airplane crashes, some concepts appear to be more resistant to releases caused by these events than others.

The drywells, the cask-in-trench, and the tunnel rack vault are more resistant to damage from the external impact events by virtue of being embedded in the soil at the site. The surface storage devices are more vulnerable to external impact events and to fires and explosions, since they are exposed above the soil surface.

A potential exists for breaching the waste canisters during handling operations. For the drywells, the emplacement of the waste canisters is done in the field where there is less control of a release of radioactive material should a canister be danaged during the emplacement operation. For the other concepts, the emplacement of canisters takes place within the confinement barriers of the Receiving and Handling facility, where the likelihood of a release of radioactive material to the environment is very low.

\subsubsection{Accident/Malfunction Recoverability}

An MRS facility must have the ability to recover from the occasional operational accidents and equipment failures and malfunctions that will occur during its operating lifetime. This ability is related strongiy to the degree of complexity of the facility operating systems.

Those concepts that utilize complex systems and equipinent may exhibit both a greater number of accidents and equipment malfunctions or failures and a greater difficulty in recovering from the incident than will those concepts that utilize simple systems and equipment. Thus, the cask and drywell concepts should experience fewer failures and be easier to recover from those failures than the more complex vault concepts. 
The simpler a concept, the easier it will be to decontaminate after an accident. The simplicity of the cask and drywell concepts makes decontamination far easier than would be the case for the vault concepts that utilize fairly complex transporters, track systems, etc.

\subsubsection{Design Testing}

Licensing of an MRS facility will require that the systems can be shown to perform their functions safely and to not endanger either the operating staff or the general public. This assurance can best be obtained from testing and operational experience with the concept.

The cask and drywell concepts have a significant data base from previous testing and operations at the Nevada Test site and at the Idaho National Engineering Laboratory. Similar experience is available for the open cycle vault, in Idaho and in the IJ.K.

No experience is available for the closed cycle and tunnel rack vaults. Thus, a significant program of prototypical testing would likely be required before these concepts could be licensed.

\subsubsection{Penetrability and Security}

All of the concepts will presumably use similar fences, guards, and surveillance equipment to prevent unauthorized intrusion into the facility. However, the candidate concepts present differing degrees of difficulty of access to the stored wastes, should an intruder evade the perimeter security system.

The cask, field drywell, and closed cycle vault concepts, being distributed throughout a large storage area, are more vulnerable to direct attack than the open cycle and tunnel rack vault concepts and the tunnel dryweli, in which an additional barrier is present in the form of a massive building or a tunnel structure.

The size of the storage area is also an important factor. A large storage area will generally have more points of possible access than will a smaller area. Also related is the ease or difficulty of visual surveillance. Observance of intruders would be easier in a drywell field than in an array of freestanding casks or an array of closed cycle vault modules. 


\subsubsection{Accountability}

Since the MRS facility will be storing material that must be kept under strict accountability, the ease or difficulty of maintaining that accountability is an important factor. The ability to perform a visual examination of the stored material varies among the candidate concepts. Only the tunnel rack vault provides the capability to visually observe all of the stored canisters at any time. All of the other concepts must rely on proper documentation of the contents of each storage device at the time of emplacement, since observation of those contents cannot be made without opening the storage unit.

Monitoring of the closures on the individual storage units provides a way to ensure that the contents remain as documented for accountability purposes. The enclosed nature of the open cycle vault makes rapid inspection of the closures possible and is amenable to the use of closed-circuit television scanners. Closure inspections for the drywell, cask, and closed cycle vault concepts are more difficult and are not generally amenable to the use of closed-circuit television scanners.

\subsubsection{Previous Licensing Experience}

None of the candidate concepts have been licensed in the U.S. to date. However, several of the concepts (concrete casks and drywells) have testing and operational experience and have had to comply with the general requirements for safety imposed by the sponsoring agency (in the U.S., by the Department of Energy). Concrete casks have also been demonstrated in Canada. Other concepts (metal casks) have been licensed in Europe. A large vault is operating in the U.K., under supervision of the national authorites, and several vaults are in operation in the U.S., in Idaho, under the supervision of the DOE. Thus, for these candidates, there are considerable data available to support a licensing action. There are no test or operating data to support a licensing action for the closed cycle and tunnel rack vault concepts.

\subsubsection{Ordinal Ranking for Safety/Licensing}

All of the candidate concepts are judged to be capable of safe operation and to be licensable. However, there are significant differences in the levels of experience avatlable to support a licensing action. Those concepts that 
have been built and operated, and/or have been licensed in other countries, clearly would be easier to license in the U.S. Those concepts that are simple in design and function will be easier to license than concepts that are relatively more complex in design.

The performances of the candidate concepts under this criterion were ranked according to the ease with which they can: conform with licensing requirements, including precluding nuclear criticality in the storage units as a result of major disruptive events; monitor the storage units to detect any leakage of radioactive material; assure the integrity of the containment of the storage units; recover from an accident, equipment failure or malfunction; make available a data base on testing of the concept; prevent intrusion, penetration or dispersion of the stored material; account for the stored material; and demonstrate previous licensing of the concepts, if any. With these factors in mind, the candidate concepts were ranked in the following order:

\begin{tabular}{cl} 
Group & \multicolumn{1}{c}{ Concept(s) } \\
\cline { 2 - 2 } & $\begin{array}{c}\text { Stationary Metal Cask, Concrete Cask, } \\
\text { Transportable Metal Cask, Field } \\
\text { Drywell, Concrete Cask-in-Trench }\end{array}$ \\
3 & Tunnel Drywell \\
4 & Open Cycle Vault \\
5 & Closed Cycle Vault \\
& Tunnel Rack Vault
\end{tabular}

Concepts of equal rank are judged to have roughly equivalent performance. While equally-ranked concepts do differ somewhat in performance, differences among concepts of equal rank are less significant than differences among concepts of unequal rank. For concepts of equal rank there is no significance to the order in which they are listed. Calculation of the ordinal rankings is discussed in Section 5.2 .

The first five concepts are judged to be nearly equal under safety/licensing, and none of the five are perceived to have significant problems with respect to ease of licensing. The remaining concepts are perceived to have 
increasing difficulty with the licensing process. Two factors dominated the ranking under this criterion: operational experience and system complexity. These factors are also related; the simpler systems were built and tested first, while the more complex systems were designed later and have yet to be built and tested.

\subsection{ENVIRONMENTAL IMPACT}

The MRS facility must prevent unacceptable releases of radioactive materials to the environment. In addition, the environmental impact of a facility depends upon the extent of modifications to the site and upon the land area required by the site. These two factors affect the ease of returning the site to other uses once MRS facilities are no longer required. The overall ranking of the candidate concepts was determined by considering their relative merits on each of the following descriptors:

- radioactivity releases

- exclusion area size

- recoverability of the area.

The principal differences among the concepts are discussed in the following sections. These discussions are followed by a listing of the ordinal ranking of the concepts under the environmental impact criterion.

\subsubsection{Radioactivity Releases}

This descriptor provides a comparison of MRS concepts with respect to their potential for release of radioactive materials into the environment and includes the intrinsic characteristics of each concept for filtering, absorbing, or holding up of radioactive materials between their release from a damaged waste package and release to the biosphere. Releasable radioactive materials from spent fuel (which poses a greater short-term concern than vitrified HLW) inciude: $85 \mathrm{Kr}$, iodine, volatile isotopes of cesium, water soluble compounds of fuel material and fusion products, and particulate aerosols from the solid waste materiais.

Static storage concepts have less potential for airborne release than concepts employing forced-air coolant. Release of radionuclides from storage positions could contaminate groundwater supplies. Surface concepts generally 
have a larger potential for airborne release than underground concepts; however, little groundwater contamination is likely. The tunnel rack vault rated somewhat lower than the other concepts on this descriptor, primarily because it has only one barrier to the release of radioactive materials. A sizable accidental release could not be easily prevented from entering the natural-draft circulating cooling air that is discharged to the atmosphere. In addition, any accidental releases would be difficult to cleanup since remote handling would be required in the storage tunnels.

\subsubsection{Exclusion Area Size}

The size of the exclusion area that is fenced to maintain safety and security and the amount of excavation needed for storage area construction will influence the perception of environmental impact for each MRS concept. In general, the larger the exclusion area the more adverse the environmental impact, assuming all other factors are equal. However, a 700 acre site reserved for spent fuel storage in a remote desert location is not equivalent to a 700 acre site in a more densely populated region.

The estimated size of the required exclusion areas for 15,000 MTU and 72,000 MTU storage facilities are shown in Table 4.1.

TABLE 4.1. Estimated Exclusion Area for 15,000 and 72,000 MTU MRS Facilities

\begin{tabular}{|c|c|c|}
\hline Concept & $\begin{array}{r}\text { Exclus ion } \\
15,000 \text { MTU }\end{array}$ & $\frac{\text { Area (acres) }}{72,000 \text { MTU }}$ \\
\hline Metal Storage Cask & 100 & 180 \\
\hline Concrete Cask & 125 & 210 \\
\hline Cask-in-Trench & 360 & 1360 \\
\hline Field Drywell & 180 & 515 \\
\hline Tunne1 Drywell & 790 & 2175 \\
\hline Open Cycle Vault & 100 & 150 \\
\hline Closed Cycie Vault & 100 & 215 \\
\hline Tunnel Rack Vault & 85 & 115 \\
\hline Transportable Cask & 105 & 190 \\
\hline
\end{tabular}




\subsubsection{Recoverability of Area}

The MRS facility is considered a means of providing temporary storage for radioactive materials. Eventually, the materials will be disposed of elsewhere, releasing the land set aside for the MRS site for other uses. This descriptor measures the relative ease of recoverability of the site for unrestricted land use or for other useful purposes.

Concepts that have extensive interaction with the site, especially through tunneling (tunnel drywell and tunnel rack vault) or excavation (cask-intrench), will require the handling of large spoils piles. These concepts were rated lowest on this descriptor. The surface cask concepts were rated highest since these would be the easiest to remove.

\subsubsection{Ordinal Ranking for Environmental Impact}

The ranking on the environmental impact criterion is as follows:

\begin{tabular}{cl} 
Group & \multicolumn{1}{c}{ Concept(s) } \\
\cline { 2 - 3 } & $\begin{array}{l}\text { Metal Cask (stationary), Closed Cycle } \\
\text { Vault, Concrete Cask, Metal Cask } \\
\text { (transportable), Open Cycle Vault, } \\
\text { Field Drywell }\end{array}$ \\
2 & Concrete Cask-in-Trench \\
3 & Tunnel Drywell \\
4 & Tunnel Rack Vault
\end{tabular}

The top six concepts are rated about equal in their performance on this criterion. Three MRS concepts are judged to be lower in overall performance on environmental impact. These three concepts--the cask-in-trench, tunnel drywell, and tunnel rack--place storage units below ground and require extensive modification of the site. All three concepts require relatively large amounts of excavation. Recoverability of the site was perceived as being somewhat more of a problem with these concepts. 
Since a monitored retrievable storage facility will be temporary, preferred MRS concepts should not require extensive, or lasting, modification to the site. The potential for radioactivity releases, while an important consideration, provided little basis for choosing among the concepts.

\subsection{SOCIOECONOMIC IMPACTS}

The expected impact of an MRS facility in the vicinity of a proposed site will influence its acceptability. Public perceptions of the storage methods, especially in terms of safety and perceived permanence, will be important factors in determining public acceptance. In addition, the potential impact on the local economy may strongly influence local acceptance. The relative merits of the candidate concepts were compared for four descriptors:

- Acceptability

- Aesthetic Considerations

- Labor Force Impacts

- Economic Impacts.

A1l of these factors will be important in determining the overall success/ feasibility of the MRS Program; however, not all of these factors are useful in discriminating among the various concepts.

The sections below contain comparisons of the concepts for each descriptor followed by a listing of the overall ranking of the concepts under the socioeconomic impact criterion, and the rationale for that ranking.

\subsubsection{Acceptability}

Acceptability is difficult to judge in advance of specific plans to actually construct a specific facility. Acceptability must necessarily depend upon the perceived safety, environmental impact, permanence, etc. of the facility. No public opinion survey was conducted. Valid measures of public preferences among the concepts would be difficult to obtain given the public's lack of familiarity with spent-fuel storage methods. Consequently, CRC members were asked to judge which factors, in their perception, would be most important in determining relative acceptability of the concepts. The emphasis is not on acceptability of MRS facilities, in general, but rather on the relative acceptability of specific concepts. 
The CRC attempted to estimate how the host community and region for an MRS facility might regard the relative acceptability of the nine concepts. Factors considered relevant included the vulnerability of the facility to natural disasters, sabotage and terrorism, and onsite accidents; how easily and reliably the stored material could be monitored; the perceived permanence of the facility; and the size of the MRS site. The tunnel rack and tunnel drywell concepts were ranked low largely because of the difficulty of monitoring for releases and the perceived permanence of such a facility (e.g., an underground facility may be perceived as a de facto repository). No consensus was reached on the relative acceptability of the remaining concepts.

\subsubsection{Aesthetic Considerations}

The second descriptor under the socioeconomic criterion-Aesthetic Considerations--focused on the appearance of the above-ground structures. The common Receiving and Handling facility would be the dominant structure for most concepts and thus reduces the significance of differences among the concepts. The surface cask concepts ranked lowest on this descriptor because of the large arrays of casks which could have a significant visual impact.

\subsubsection{Labor Force Impact}

Initial construction and expansion of facilities will induce changes in the size of the labor force required in the vicinity of the site. The nature

of labor force impacts is very dependent upon specific site characteristics. A larger labor force may be more desirable in one location and less desirable in another location. The concepts do, however, differ in the degree of fluctuation in work force size throughout their operating lifetimes. Steady labor requirements are preferred--are less disruptive to the local economy--than are fluctuating labor requirements.

The tunnel rack vault and tunnel drywell concepts all require storage capacity additions in large increments and thus would have correspondingly larger fluctuations in the labor force. The concrete cask-in-trench concept requires periodic excavation of trenches for emplacement of the casks, thereby causing some fluctuations in the labor force. The surface cask concepts and the field drywell expand their storage capacities in small increments and would maintain relatively steady employment levels. 


\subsubsection{Economic Impact}

For comparison purposes, the CRC assumed that total economic impact in the vicinity of the site would be a function of the total labor force-without regard to fluctuations--and the total construction and operating cost. As was the case with Labor Force Impacts, the variation in the merits of these concepts will be overshadowed by variations across sites. There was not a significant degree of discrimination on this descriptor.

\subsubsection{Ordinal Ranking for Socioeconomic Impact}

The ranking on the socioeconomic criterion is as follows:

\begin{tabular}{|c|c|}
\hline Group & Concept $(s)$ \\
\hline 1 & $\begin{array}{l}\text { Closed Cycle Vault, Open Cycle Vault, } \\
\text { Field Drywell, Metal Cask (Transportable) }\end{array}$ \\
\hline 2 & $\begin{array}{l}\text { Concrete Cask, Concrete Cask-in-Trench, } \\
\text { Metal Cask (Stationary), Tunnel Drywell }\end{array}$ \\
\hline 3 & Tunnel Rack Vault \\
\hline
\end{tabular}

Of all the ranking criteria, socioeconomic impact is the least useful for differentiating the alternative concepts. This is due, in part, to the lack of consensus on what constitutes preferred performance on factors such as acceptability or aesthetics. One basis for differentiating concepts, however, is the magnitude of work force fluctuations. Concepts with relatively small work force fluctuations tend to rank high, while concepts requiring large fluctuations in the size of the work force tend to rank low.

\subsection{SITING REQUIREMENTS}

A key consideration in selecting an MRS concept is that it be relatively easy to find suitable sites. In its role as back-up to the repository, the MRS must provide high assurance of timely deployment. While site selection for a repository depends upon detailed characterizations of site geology and hydrology, preferred MRS concepts exhibit a degree of independence from geologic characteristics (e.g., thermal, seismic, and soil or rock chemistry) and hydrologic characteristics (e.g., groundwater, precipitation, and flooding). 
Four descriptors define this criterion:

- Land Requirements

- Geological Requirements

- Hydrological Requirements

- Resource Requirements.

The following sections summarize the relative merits of the candidate concepts for each of the descriptors. The final section presents a listing of the overall ranking under this criterion, and the rationale for that ranking.

\subsubsection{Land Requirements}

Concepts requiring more land area to store a given quantity of material place more stringent restrictions on site selection. The importance of this descriptor, however, depends upon the specific site being considered. The amount of land area required in a remote desert location is a relatively insignificant consideration compared with a wooded eastern site having many alternative uses. In the overall ranking under the Siting Requirements criterion, this descriptor was relatively unimportant. The land requirements for the concepts are given in Section 4.2.2, Exclusion Area Size.

\subsubsection{Geological Requirements}

A storage concept's sensitivity to or dependence on thermal and seismic considerations and rock chemistry is considered under this descriptor. The thermal properties of the host rock are important to certain concepts for maincaining the temperatures of the stored material within allowable limits. The ability of a storage concept to isolate the stored material from seismic occurrences is also a safety consideration. Chemical corrosion is an important factor in considerations concerning the long-term integrity of the storage containers.

Concepts with a greater degree of isolation from geological conditions, i.e., those that do not rely on geological conditions for safe, reliable containment of stored materials, are preferred. Accordingly, the surface cask concepts and surface vaults (open cycle and closed cycle vaults) ranked highest on this descriptor since they are air-cooled and above-ground. The drywell 
concepts, cask-in-trench, and tunnel rack vault ranked lowest because of their dependence upon geological conditions for cooling and/or structural integrity of storage areas.

\subsubsection{Hydrological Requirements}

Hydrological requirements measure the degree of interaction between the storage concept and the surrounding groundwater and surface drainage systems. Close interaction between the storage concept and the hydrology could make the storage concept more susceptible to failure and could provide a pathway for release of radioactive materials. Concepts with in-ground storage locations place more stringent requirements on site selection. Preferred concepts are relatively independent of hydrological properties.

The relative merits of the concepts followed the same pattern as for Geological Requirements. In-ground and subsurface concepts ranked lowest and the surface casks and vaults ranked highest.

\subsubsection{Resource Requirements}

Concepts may place restrictions on siting by requiring resources such as water and construction materials. The common Receiving and Handiing facility places a similar requirement for such materials on all concepts, except for the transportable metal cask, which has a somewhat smaller R\&H facility, as noted earlier. The concrete cask concepts may utilize onsite fabrication of storage casks and thus have somewhat larger local resource requirements than the other concepts. Overal1, this descriptor does not provide a significant degree of discrimination among the candidate concepts.

\subsubsection{Ordinal Ranking for Siting Requirements}

The ranking of the concepts with respect to siting requirements is:

\begin{tabular}{|c|c|}
\hline Group & Concept (s) \\
\hline 1 & $\begin{array}{l}\text { Open Cycle Vault, Metal Cask, (Stationary) } \\
\text { Metal Cask (Transportable) }\end{array}$ \\
\hline $\begin{array}{l}2 \\
3 \\
4 \\
5 \\
6\end{array}$ & $\begin{array}{l}\text { Concrete Cask } \\
\text { Closed Cycle Vault } \\
\text { Tunnel Rack Vault } \\
\text { Concrete Cask-in-Trench, Field Drywell } \\
\text { Tunnel Drywell }\end{array}$ \\
\hline
\end{tabular}


Above-ground concepts $\rightarrow$ casks and vaults-rrank highest on this criterion because of their relative independence from the site. They have the fewest siting requirements. Below-ground concepts--the drywells and the concrete cask-in-trench--transfer heat to the ground, and siting has to take thermal and chemical interactions into account. Similarly, below-ground concepts have greater potential for interaction with hydrologic characteristics and have to be sited accordingly.

\subsection{COST CRITERION}

Construction, operation, and decommissioning of an MRS facility requires expenditure of a significant amount of money. These expenditures depend upon the storage concept chosen. As the custodian of the Waste Fund, the Department of Energy is expected to use those funds in a cost-effective manner. Thus, the total MRS life-cycle costs should be minimized. Also, the life-cycle costs should be relatively insensitive to the form of the material requiring storage and to changes in operational requirements (throughput, storage capacity). Overall performance of the candidate concepts on cost was determined by considering the relative merits of each concept for each of the following three descriptors:

- life-cycle cost

- cost sensitivity

- cost-estimating confidence.

The principal differences between storage concepts relative to each of these descriptors are discussed in succeeding sections. These discussions are followed by a listing of the ordinal ranking for the concepts under the cost criterion and the rationale for that ranking.

\subsubsection{Life-Cycle Costs}

Life-cycle costs consist of three principal components: construction or capital costs, operation costs, and decommissioning costs. Construction costs include the costs of design, site development, licensing, testing, and operational (startup) testing. Some of the concepts require extensive excavation or fabrication of special equipment, thus increasing the initial capital cost of the facility. 
Operational costs include the routine handling, storage, and retrieval of stored radioactive materials. Other tasks include maintenance, security, monitoring, environmental control, and the possible cleanup of storage positions. The costs of performing these tasks are dependent upon the particular storage concept chosen. Storage concepts that utilize complex equipment, or that require more time to accomplish the facility's function, will cost more to operate.

Decommissioning costs can also vary, depending upon the details of the storage concept. For purposes of normalization, the cost of decommissioning was defined to be $10 \%$ of the capital cost of those structures and components that are likely to become contaminated during the life of the facility. In general, the larger the capital cost, the larger the expected cost of decommissioning.

Estimates of the magnitudes of the components of the life-cycle cost for each of the candidate storage concepts are given in Table 4.2 , based upon the common scenario used for concept normalization (1800 MTU/yr throughput, 15,000 MTU total storage capacity), and/or an expanded capacity (72,000 MTU) facility.

TABLE 4.2. Estimated Life-Cycle Costs for Candidate Concepts in Millions of Undiscounted 1983 Dollars

\begin{tabular}{|c|c|c|c|}
\hline Concept & $\begin{array}{r}\text { Life-Cycie } \\
\frac{15,000}{\text { Consolidated }} \\
\text { Spent Fuel } \\
\end{array}$ & $\frac{\text { sts }}{\mathrm{HLW} / \mathrm{TRU}}$ & $\begin{array}{l}72,000 \mathrm{MTU} \\
\text { Consolidated } \\
\text { Spent Fuel }\end{array}$ \\
\hline Field Drywell & 647 & 626 & 1749 \\
\hline Concrete Cask & 823 & 866 & 2671 \\
\hline Tunnel Rack Vault & 853 & 914 & 2082 \\
\hline Closed Cycle Vault & 946 & 1446 & 3067 \\
\hline Open Cycle Vault & 1012 & 943 & 3815 \\
\hline Transportable Metal Cask & 1115 & 2547 & 4639 \\
\hline Tunnel Drywell & 1216 & 1028 & 4194 \\
\hline Stationary Metal Cask & 1345 & 2802 & 4868 \\
\hline Concrete Cask-in-Trench & 1521 & 1515 & 7411 \\
\hline
\end{tabular}




\subsubsection{Cost Sensitivity}

It is important that the unit cost for storage of waste materials be relatively insensitive to the system requirements that may eventually be placed on the MRS. For example, it should be possible to increase the rate at which wastes can be received and stored at MRS without significantly increasing the unit cost of storage. Also, it should be possible to increase the capacity of the storage arrays to accommodate a larger inventory of wastes with the same or a reduced unit cost of storage. In addition, the unit cost of storage should be relatively insensitive to the form of the stored material (spent fuel or solidified reprocessing waste).

The sensitivity of the estimated life-cycle costs of the candidate concepts to differences in waste form and to storage capacity is shown in Table 4.2. The field drywell, concrete cask, and tunnel rack vault concepts are seen to be the least sensitive to changes in waste form and storage capacity.

\subsubsection{Confidence in Cost Estimate}

The confidence that can be placed in the validity of the estimates of concept life-cycle costs is largely determined by the experience that has been accumulated on the construction and operation of a given storage concept. Concepts that have already been built and operated, even on a pilot scale, can have their costs estimated with a much higher level of confidence than a concept that has never been built or tested.

The concrete cask, field and tunnel drywell, and the metal cask all have a significant data base on construction and operation, at the Nevada Test Site, in Canada, and for the metal cask, all over the world. The concrete cask-intrench is rather similar to both a concrete cask and to a drywell. Thus, a high degree of confidence is possible in the estimation of costs for construction and operation of these concepts.

A variety of dry open cycle vault storage systems have been built and operated in the United Kingdom (Wyfla), and in the U.S. (Idaho National Engineering Laboratory). While these systems are not identical with the design 
evaluated in this study, they are sufficiently similar to provide reasonable confidence in the estimation of the cost of construction and operation for this concept.

The tunnel rack and closed cycle vaults have no history of previous construction and operation. Thus, the confidence level for the cost estimates for these concepts has to be considerably lower than for concepts that have been built and operated, even only on a pilot scale.

\subsubsection{Ordinal Ranking for Cost}

The key items of consideration under the cost criterion are the system life-cycle cost, the sensitivity of that cost to changes in the mission of the MRS facility, and the level of confidence that can be placed in the estimates of the life-cycle expenditures. With these factors in mind, the candidate concepts were ranked in the following order:

\begin{tabular}{cl} 
Group & \multicolumn{1}{c}{ Concept(s) } \\
\cline { 2 - 2 } 2 & Field Drywell \\
3 & Concrete Cask \\
4 & Open Cycle Vault, Tunnel Rack Vault \\
5 & $\begin{array}{l}\text { Closed Cycle Vault, Transportable } \\
\text { Metal Cask, Tunnel Drywell }\end{array}$ \\
6 & Stationary Metal Cask \\
& Concrete Cask-in-Trench
\end{tabular}

The field drywell and the concrete cask were ranked highest because of their lower unit cost for storage, their low sensitivity to changes in waste form and capacity requirements, and because of the higher confidence that could be placed in the estimates of their costs resulting from their history of testing and demonstration.

\subsection{CONCEPT MATURITY CRITERION}

Well-developed, demonstrated concepts have few research and development needs and do not require excessive conservatism in their design because of uncertainties. Therefore, well-developed concepts can be deployed in times 
that are shorter than the deployment times for the less-developed concepts. Overall performance of the candidate concepts on concept maturity was determined by considering the relative merits of each concept for each of the following six descriptors:

- concept development

- research and development requirements

- conservatism needed

- deployment time

- storage retrievability

- engineering simplicity.

The principal differences among storage concepts relative to each of these descriptors are discussed in succeeding sections. These discussions are followed by a listing of the ordinal ranking for the concepts under the concept maturity criterion, and the rationale for that ranking.

\subsubsection{Concept Development}

Some of the candidate concepts have well-developed demonstration facilities and have a history of successful operation. Other concepts have little or no demonstrated experience base. The concrete cask has extensive test and operational experience in Canada and at the Nevada Test Site (E-MAO). The field drywell has many years of operational experience at the Idaho National Engineering Laboratory, as well as test experience at E-MAD. Test experience with the tunnel drywell has been obtained in the Climax mine at the Nevada Test Site. Several vault designs have been in operation in Idaho and in the United Kingdom for a number of years. While these vaults are not identical with the open cycle vault concept, they are sufficiently similar to provide confidence that the open cycle vault could be successfully built and operated safely. The concrete cask-in-trench is an untested concept, but is so similar to a drywell in configuration that there is confidence that the storage unit would operate as designed. Long-term storage in metal casks also has not been demonstrated. However, there have been many years of experience accumulated in building and using metal casks for shipment of radioactive materials throughout the world. Based on this experience, there is confidence that the metal casks could successfully be utilized for both transport and long-term storage of spent fuel or 
solidified high-level waste. The closed cycle vauit has been neither built nor operated. While it utilizes developed technology, use of that technology in this application has not been demonstrated, lessening the level of confidence in the concept. Like the closed cycle vault, the tunnel rack vault has been neither built nor operated. While it is similar in many respects to the open cycle vault, the complexity of the remotely-operated systems lessens confidence in its ability to perform successfully.

\subsubsection{Research and Development Requirements}

While the MRS Research and Development Report to Congress (OOE 1983) stated that the proposal to Congress mandated by the NwPA could be completed without any further research and development, it was noted therein that some further work in selected areas might be helpful in contributing to a more efficient design, improving safety, or facilitating licensing. These areas of work are principally in the development of specific information or data related to specific needs. The needs for the candidate concepts are summarized below.

Some benchinark data are available for drywells and concrete casks, but 1 ittle or no data are available from metal casks or from any of the vault concepts for use in evaluating methods of analysis. Further work is needed to demonstrate the performance of the heat pipe system for the closed cycle vault.

Considerable developinent and demonstration work would be appropriate for the tunnel rack vault to assure that the natural circulation cooling system could function and still permit confinement of any releases of radioactive material into the cooling air. Demonstration of the complex remote-handling systems would aiso be required before licensing could be accomplished.

Development and demonstration of appropriate impact limiters for the transportable metal cask would be necessary before it could be licensed for transport.

Further studies related to the potential for corrosive failure of drywells over the long time span possible for MRS may be needed to assure confinement of the stored radioactive materials. 


\subsubsection{Conservatisin Needed}

The degree of conservatism needed in design of an MRS is dependent upon the developmental status of the concept and the remaining uncertainties that must be resolved prior to deployment. Conservatism can be reduced for concepts that have a history of satisfactory performance. Conversely, concepts without a history of performance require more conservatism in their design to ensure a satisfactory result.

The drywells and the concrete casks have a significant body of historical performance data to support their design and little conservatism would be necessary.

The vault concepts have some similar facilities in service to provide confidence in the principal design parameters, but each of the vault concepts has design areas that remain to be demonstrated, thus requiring considerable conservatism to be incorporated into the design of those areas.

The metal casks have many years of performance in service as shipping devices, and confidence is high that these units can be designed to perform as required without significant design conservatism.

\subsubsection{Deployment Time}

The time required to deploy an MRS concept directly affects the planning processes for an MRS. To maxinize the system flexibility, concepts with short deployment times would be desirable. Assuming that the necessary development/ demonstration work has been accomplished in a timely manner, all of the concepts could be deployed in approximately the same time period, which is controlled by the time required for construction of the Receiving and Handling facility. However, starting from now, those concepts indicated above as requiring further development and demonstration would be slower to deploy, since that development and demonstration work would have to be completed before final design could be completed and construction could commence.

\subsubsection{Storage Retrievability}

Retrievability is the key feature of an MRS facility. The stored spent fuel or waste materials must be retrievable in the event that a container 
begins to leak radioactive material or when final disposition of the stored material is initiated, e.g., by opening of a fuel reprocessing plant or a deep geologic repository.

The drywells, the surface storage casks (both metal and concrete), and the open and closed cycle vaults all permit relatively rapid random access to storage locations for retrieval of stored material. The cask-in-trench concept would require excavation of the cask prior to retrieval, thus making that activity more costly and time consuming. The tunnel rack vault operates on a first-in, last-out storage arrangement. Thus, retrieval of a canister stored early in facility life could require the movement of a large number of racks of stored material, a costly and time-consuming process, potentially hazardous to the stored material.

\subsubsection{Engineering Simplicity}

There is an engineering axiom to the effect that the simpler a system is, the less there is to go wrong. A corollary is that the simpler the system, the less it costs to build and operate. Therefore, there are incentives for keeping an engineered system as simple as possible.

The cask concepts are very simple, with all handling of radioactive materials taking place within the confines of the Receiving and Handing facility. The only field operations involved are transport and placement of the sealed casks.

The drywells are also quite simple devices, utilizing the surrounding soil to absorb the enitted radiation and to transfer the decay heat from the stored materials to the atmosphere. However, a shielded transfer device is required to transport and emplace the canisters of radioactive material in the drywelis.

The open cycle vault is somewhat more complex in its cooling system and requires a shieided transporter for emplacement.

The closed cycle vault has a more complex cooling system involving heat pipes, and it requires a shielded transfer device for emplacement. 
The tunnel rack vault has a very complex mechanical transfer and emplacement system that must be operated, and possibly maintained, remotely. The natural circulation cooling system is basically simple, but installation of confinement capability could greatly complicate the system.

\subsubsection{Ordinal Ranking for Concept Maturity}

Mature storage concepts should have few, if any, research and development needs; a history of satisfactory performance, which in turn provides confidence that the system will function reliably; and the ability to be deployed more quickly, probably at lower cost. Less conservatism would be required in the design to assure satisfactory performance. With these factors in mind, the candidate concepts were ranked in the following order:

\begin{tabular}{cl} 
Group & \multicolumn{1}{c}{ Concept (s) } \\
& Field Drywell \\
3 & Concrete Cask, Tunnel Drywell \\
4 & Metal Cask (stationary) \\
& $\begin{array}{c}\text { Open Cycle Vault, Metal Cask } \\
\text { (transportable), Concrete } \\
\text { Cask-in-Trench }\end{array}$ \\
5 & Closed Cycle Vault \\
6 & Tunnel Rack Vault
\end{tabular}

The drywell concepts and the concrete cask were ranked highest because of their long history of testing and operation and because they are simple devices. The two concepts that were ranked lowest (closed cycle and tunnel rack vaults) have no testing and demonstration history and are relatively complex systems.

\subsection{FLEXIBILITY}

The currently defined role of the MRS system is to provide back-up storage in the event of delay in deployment of geologic repositories. Consequently, neither the timing nor the level of demand for MRS services can be accurately predicted. In addition, other nuclear waste management decisions, such as the startup of spent fuel reprocessing, could aiter MRS operational requirements. Reprocessing, for example, would influence the types of waste forms and package 
configurations to be handled. Avajlability of storage capacity at reactors or at reprocessing plants would influence the rate at which waste must be placed in MRS. Idealiy, the MRS system should have the flexibility needed to accommodate changes in the waste acceptance rate, storage capacity, and waste form. In addition, an MRS facitity should be easily adaptable to a variety of sites. Two additional factors contribute to the flexibility of a concept: recoverability of capital assets, and critical resource consumption. Since the MRS facility is intended as a temporary component of the waste management system, it is desirable that any scarce or nonrenewable resources used be recoverable from the facility. In addition, concepts that use scarce materials such as chromium, lead, or nickel could be susceptible to disruptive material shortages or price escalation.

Overall performance on flexibility was determined by separately considering the relative merits of the candidate concepts on the following six descriptors:

- Site Adaptability

- Expandability of Throughput Rate and Capacity

- Sensitivity to Waste Form

- Heat Load Sensitivity

- Recoverability of Capital Assets

- Critical Resource Consumption.

The key differences among concepts for each descriptor are explained below, followed by the overall ranking on flexibility and the rationale for that ranking.

\subsubsection{Site Adaptability}

The MRS concept should provide as much siting flexibility as possible to preserve siting options and minimize the amount of site-specific information needed to design, license, and safely operate an MRS facility. The surface cask concepts (the concrete and metal storage casks) and the surface vaults (the open cycle and closed cycle vaults) are the most adaptable to a variety of siting conditions. None requires restrictive site characteristics. The field drywell and concrete cask-in-trench are less flexible, since sites generally must be chosen so that the storage units are above the groundwater level. 
Alternatively, an earthen berm could be constructed to raise the drywells and casks-in-trench above the groundwater level. The tunnel drywell and tunnel rack vault concepts are the least adaptable to various siting conditions, since suitable terrain, e.g., a mountain, is required. As an alternative, a cut-andcover technique could be employed.

\subsubsection{Expandability of Throughput Rate and Capacity}

In its role as back-up to the repository, the level of demand for the MRS facility will depend upon other components of the waste management system, including the actual repository deployment and provisions for at-reactor storage. Incremental additions to capacity are most easily achieved with the field drywell and surface cask concepts. The open and closed cycle vaults and the cask-in-trench require additional capacity to be added in larger increments. The tunnel concepts--tunnel drywell and tunnel rack vault--require the most effort to expand. Addition of tunnels must necessarily add capacity in much larger increments than do the other concepts.

Expansion of throughput rate is determined by the common receiving and handling facility; consequently, the transportable metal cask, with its reduced handling requirements, is the least constrained in terms of expansion of throughput rate.

\subsubsection{Waste Form Sensitivity}

The NWPA requires that DOE prepare designs for MRS facilities "to accommodate spent nuclear fuel and high-level radioactive waste resulting from civilian nuclear activities." Since only a small quantity of commercially generated HLW exists and plans for further reprocessing are on hold, the primary material for storage is assumed to be spent fuel. Nevertheless, the selected concepts should not be overly sensitive to a requirement to store $H L W, i . e .$, extensive design changes should not be required to accommodate HLW.

All of the concepts would require some minor changes in storage configurations to accommodate HLW and its associated RHTRL. These changes, however, are not judged to be significant. The drywell concepts would use the same basic design for HLW only with a shorter (shallower) drywell. The metal and concrete cask concepts are designed to handle multiple stcrage canisters of either spent 
fuel or HLW. Internal baskets can easily be modified to accommodate appropriate arrangements of storage canisters. The closed cycle vault concept accommodates other waste forms in a similar manner to the cask concepts. Both the open cycle and tunnel rack vaults require minor modification to accommodate other waste forms.

\subsubsection{Heat Load Sensitivity}

The DOE is obligated under 10 CFR 961 to accept 5-year cooled spent fuel from utilities. However, the bulk of the spent fuel that could be stored in an MRS facility would be cooled for a much longer period, e.g., 10 years or more. Sufficient heat removal must be assumed to maintain waste temperatures within specified limits (see Section 3.2). The candidate MRS concepts differ in the ease with which they accommodate materials of differing heat loads. The vault concepts are the least sensitive to heat load due to their designs, which facilitate convective heat flow from the storage canisters. If necessary, the heat loading in canisters can be adjusted. The drywell concepts and the concrete cask-in-trench are the most sensitive to heat loading. For cask concepts, the internal loading would have to be adjusted to meet internal temperature limits. More casks (increasing storage costs) would be needed to accommodate the sane quantity of material with higher heat loading.

\subsubsection{Recoverability of Capital Assets}

Congress specified that the MRS facility safely store spent fuel and waste, as long as may be necessary, and provide for ready retrieval of the stored materials. MRS is temporary. This descriptor measures the degree to which useful assets can be recovered and used elsewhere in the waste management system. The metal cask concepts stand out on this measure since some could conceivably be used for storage, or transportation, at other locations. None of the other concepts have major reusable components.

\subsubsection{Critical Resource Consumption}

The MRS concept should not be overly susceptible to delays that would prevent it from being deployed on time or expanding storage capacity as appro-

priate. The factors in such delays could be shortages or price escalations in scarce materials such as chromium, lead, or nickel. In addition, nonrenewable 
energy resources used in construction could also inhibit timely expansion or induce unexpected construction cost escalation. None of the concepts have serious limitations in this area. However, the metal cask concepts use critical resources most intensively in their designs. Their Jower performance on this descriptor tends to counter-balance their higher performance on the previous descriptor--recoverability of capital assets. Consequently, these two descriptors had no net effect on the ranking on the concepts for the flexibility criterion.

\subsubsection{Ordinal Ranking for Flexibility}

The ranking for the flexibility criterion is:

\begin{tabular}{cl} 
Group & \multicolumn{1}{c}{ Concept(s) } \\
\cline { 2 - 3 } & $\begin{array}{l}\text { Metal Cask (Transportable), Open Cycle } \\
\text { Vault, Concrete Cask, Field Drywel1 } \\
\text { Metal Cask (Stationary), Closed Cycle } \\
\text { Vault, Concrete Cask-in-Trench }\end{array}$ \\
2 & Tunnel Rack Vault, Tunnel Drywell
\end{tabular}

The top seven concepts are judged to have high performance on this criterion. None would have significant problems adapting to a variety of siting conditions, meeting any likely throughput rates, or handling the anticipated range of heat loads or waste forms. There is some variation among the top seven concepts in their relative performance on these aspects of flexibility, but all are judged to have a high degree of flexibility.

Only two concepts, the tunnel drywell and the tunnel rack vault, are found to have significantly less flexibility. The commonality between these concepts, and the feature that differentiates them from the other concepts, is their requirement for extensive modification of the site, in order to accommodate additional storage capacity. Poor performance on flexibility is thus manifested through their more extensive interaction with, and modification of, the site. 


\subsection{COMPOSITE RANXING RESULT}

The previous section summarized the ordinal ranking result for each criterion. Since the evaluation criteria were not judged to be of equal importance in evaluating the overall merits of the concepts, the Criteria Weighting Committee (CWC) assigned weights to the various criteria. These weights were then used in combination with the ordinal rankings to compute a composite ranking. The sensitivity of this composite ranking to variations in the assumed criteria weights was tested to determine the stability of the ranking result. As a result of these tests, three of the candidate concepts were clearly inferior to the others. Consequently, the composite ranking and associated sensitivity analysis reported in this section served to narrow the field of concepts under consideration.

\subsection{ASSIGNMENT OF WEIGHTS TO EVALUATION CRITERIA}

The seven evaluation criteria were not considered to be of equal significance in selecting an MRS concept. To adequately incorporate these differences into the evaluation process, numerical weights were assigned, corresponding to each criterion's perceived relative importance in MRS concept selection. These weights were derived from data provided by the Criteria Weighting Committee (CWC). The CWC consisted of six senior PNL staff selected for their broad perspective on nuclear waste management issues. These committee staff had a broad mix of relevant technical and management backgrounds, including environmental, health and safety, engineering and cost.

The committee members met several times prior to the ranking activities described in Section 4 to discuss the MRS mission and the evaluation criteria. These discussions served to clarify the meaning of the criteria and to highlight differences between the factors which made the criteria important in selecting an MRS concept. On the basis of these discussions, committee members individually completed matrices of pairwise comparisons indicating the relative importance of the criteria. The entries within each matrix reflected the subjective assessments of the relative importance of each criterion with each other criterion as expressed on a nine point scale. To develop the criteria 
weights, these matrices were combined using a systematic procedure called the Analytic Hierarchy Process (Saaty 1980). The CWC also clarified the meaning and interpretation to be given to the criteria and descriptors.

The results of the criteria weighting were as follows:

\begin{tabular}{lll}
\multicolumn{1}{c}{ Criterion } & & Weight \\
Safety/Licensing & & 0.43 \\
Environmental Impact & & 0.11 \\
Socioeconomical Impact & 0.05 \\
Siting Requirements & 0.09 \\
Cost & 0.10 \\
Concept Maturity & 0.12 \\
Flexibility & $\underline{0.10}$ \\
$\quad$ Total & 1.00
\end{tabular}

The CWC members concluded that safety and licensing should receive the highest weight in selecting MRS concepts. The concepts chosen should have features that minimize the need for excessive design conservatism and additional performance verification.

Socioeconomic impact was assigned a lower weight than the other criteria because differences in these impacts are most significant once specific sites are known. Differences across concepts in socioeconomic impact were not felt to be important considerations in concept selection. Concept maturity, environmental impact, cost, flexibility, and siting requirements were all assigned roughly equal weights.

\subsection{CALCULATION OF ORDINAL RANKS}

Ordinal rankings were used throughout this evaluation. An ordinal ranking simply orders the concepts according to their relative merits. Rank numbers are assigned from 1 to 9 , with 1 being highest, or best. Ordinal rank numbers are used to indicate the relative order of the concepts and do not reflect how much better one concept is than another. Concepts ranked 1 and 2 may be much closer than concepts ranked 8 and 9 , or vice versia. When two or more concepts 
are tied, the positions for which the concepts are tied are averaged, and that average becomes the ordinal rank for each concept. For example, if two concepts are tied for first and second, their ranks are 1.5. If two concepts are tied for 8th and 9th, their ordinal rank are 8.5. Although concepts that are tied may differ in their relative merits, these differences are less significant than are differences among concepts of unequal rank.

Each member of the Concept Ranking Committee (CRC) produced an ordinal ranking of the candidate concepts for each of the seven evaluation criteria and provided a written rationale to support the ranking. Also, the relative merits of the concepts for each descriptor under the criterion were judged, using a high/medium/low scale. These ratings were used to improve the degree of consensus among committee members, not to compute an individual member's ranking for that criterion.

Although efforts were made to improve consensus among members, the rankings from each committee member differed somewhat because of differing judgments concerning the importance of the various descriptors within each criterion. The various rankings for each criterion were combined using a mathematical algorithm (Cook and Seiford 1982) that locates the ordinal ranking that most closely approximates the rankings from the individual members. In computing the final ranking, the algorithm, in effect, finds the ordinal ranking that is closest to the average ranking--where each concept's average ranking is the average of the ordinal ranks assigned to it by the committee members. The final ranking may contain ties. When the average ranks of two or more concepts are "close," their final ordinal rank will be identical. Formally, the final ranking is the ordinal ranking that minimizes the squared distance (referred to as $\mathrm{s}^{2}$ ) from the average ranking. No other ordinal ranking provides a better "fit" to the data--i.e., the individual rankings. This approach tends to separate the concepts into groups with roughly equivalent performance. It does not provide precision with respect to the smaller differences between concepts of equal rank. That precision is addressed later in the detailed pairwise comparison of concepts. 
The ranking results by criterion are displayed in Table 5.1. For each criterion, the average rank and the final ordinal rank are shown. For a given concept, the average rank is the average of the ranks assigned to that concept by all CRC members. The final ranking is the ordinal ranking that is "closest" to the ordinal rankings from the committee members. The distance between the final ordinal ranking and the average of the rankings from the committee mem-

bers (shown as $s^{2}$ in Table 5.1) measures the degree of consensus among CRC mernbers. Consensus was lowest for the socioeconomic criterion. Consensus was higher for safety/licensing, siting requirements, cost, and concept maturity. Generally, criteria for which consensus was lower will provide less discrimination among the concepts in the final ranking results.

\subsection{CALCULATION OF COMPOSITE RANKS}

The ordinal rankings of concepts for each criterion were combined with the criteria weights to form a composite ranking. The ordinal rankings for highly weighted criteria influence the composite ranking more than the rankings for less important criteria. Thus, the ranking of the concepts for safety/licensing had the greatest influence on the composite.

The method of computing the composite ranking is analogous to that used to arrive at the ranking results by criterion. The only change from the prior calculation was that a "weighted average rank" was computed. instead of an average rank. The same algorithm was used to locate the closest ranking to this weighted average ranking.

The composite ranking result is shown in Table 5.2 along with the criteria weights, ordinal rankings by criterion, and the weighted average ranks. Concepts are displayed in order of their weighted average ranks. The field drywell and the concrete cask have the two best weighted average ranks. Nevertheless, in the composite ranking these concepts are tied with the two metal cask concepts. An ordinal ranking with the top four concepts tied with one another closely fits the ranking data (i.e., it minimizes the distance between the composite ranking and the weighted average ranking). 
TABLE 5.1. Ranking Results by Criterion

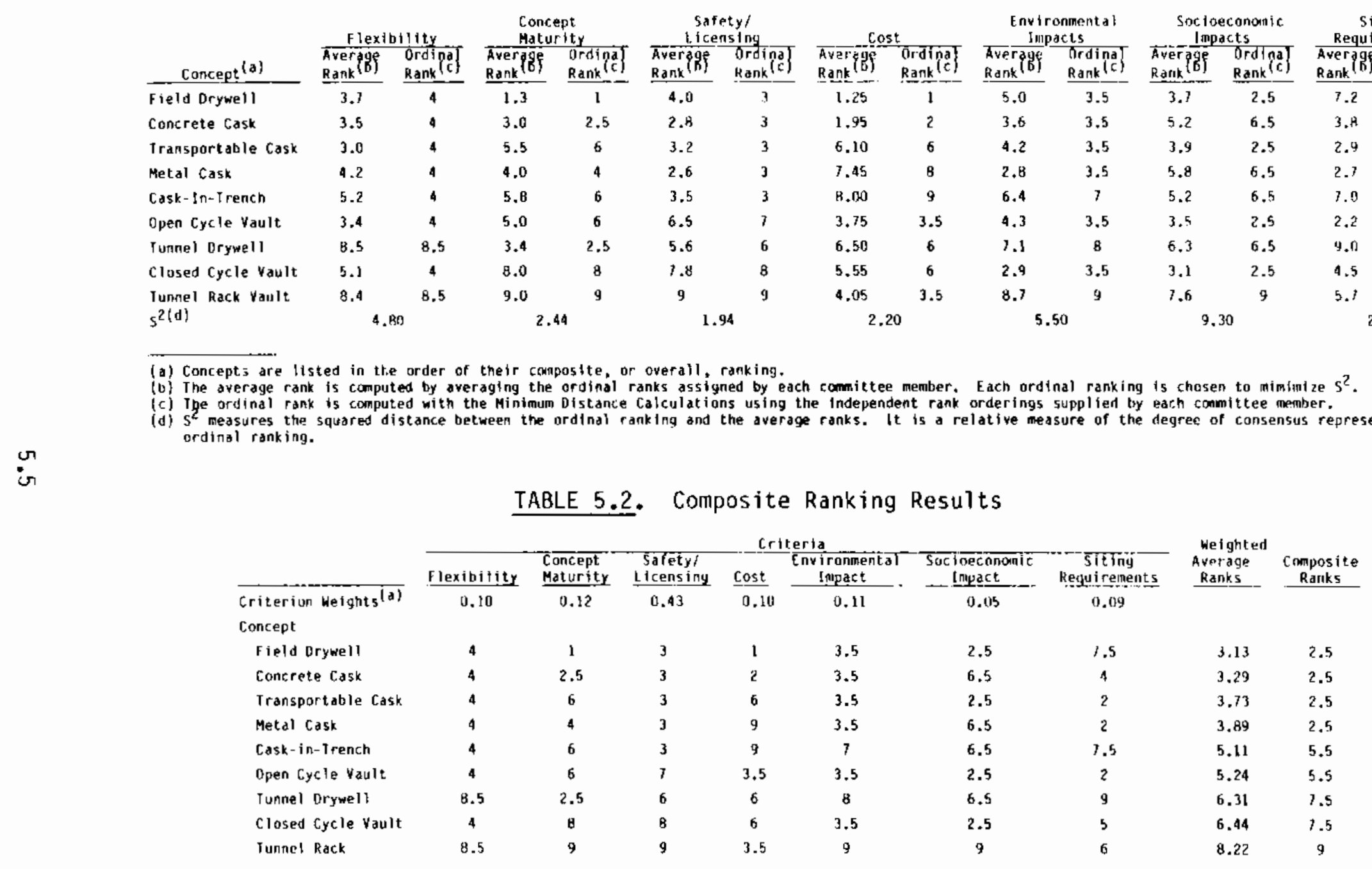

(a) Criterton weights calculated by averaging the weights assigned to each criterton by the fndividual members of the Criterta
Weighting Comnitte?. 


\subsection{SENSITIVITY ANALYSIS}

The combination of ordinal ranks and criteria weights allows significant differences among the concepts to be readily identified. It does, however, tend to obscure the smaller differences among concepts. To determine the significance and stability of differences among concepts, the sensitivity of the composite ranking result to changes in the criterion weights was tested. This section describes the effects of these variations on the composite ranking results.

Table 5.3 displays the base case results (and weights) along with the results from eight additional cases. Case 2 in Table 5.3 computes a composite ranking by combining the average ranks by criterion (instead of the ordinal ranks, see Table 5.1) with the criteria weights. The top six concepts are tied using this method. The other three concepts are still significantly lower in overall performance.

Cases 3 through 8 compute the composite rankings that result from the weights assigned by each of the six Criteria Weighting Committee (CWC) members. Although these weights vary significantly, the field drywell and concrete cask always appear in the top tier of concepts. The top six concepts all appear tied for highest rank for at least one set of weights.

Case 9 assigns equal weight to each criterion. Six concepts tie for the highest rank with this assumption.

The results shown in Table 5.3 demonstrate the stability of the ranking results. The field drywell and the concrete cask always appear in the top tier of concepts. The two metal casks generally rank in this highest tier, except when cost is given relatively more weight (Cases 4 and 7 ). These results indicate that the top six concepts are fairly close in overall performance for the seven criteria used in this evaluation. Consequently, in order to provide a sound basis for selecting the two concepts for further design, the specific differences among the top concepts were examined in greater detail using the pairwise comparisons described in the following section. 
IABLE 5.3. Sensitivity Analysis Results

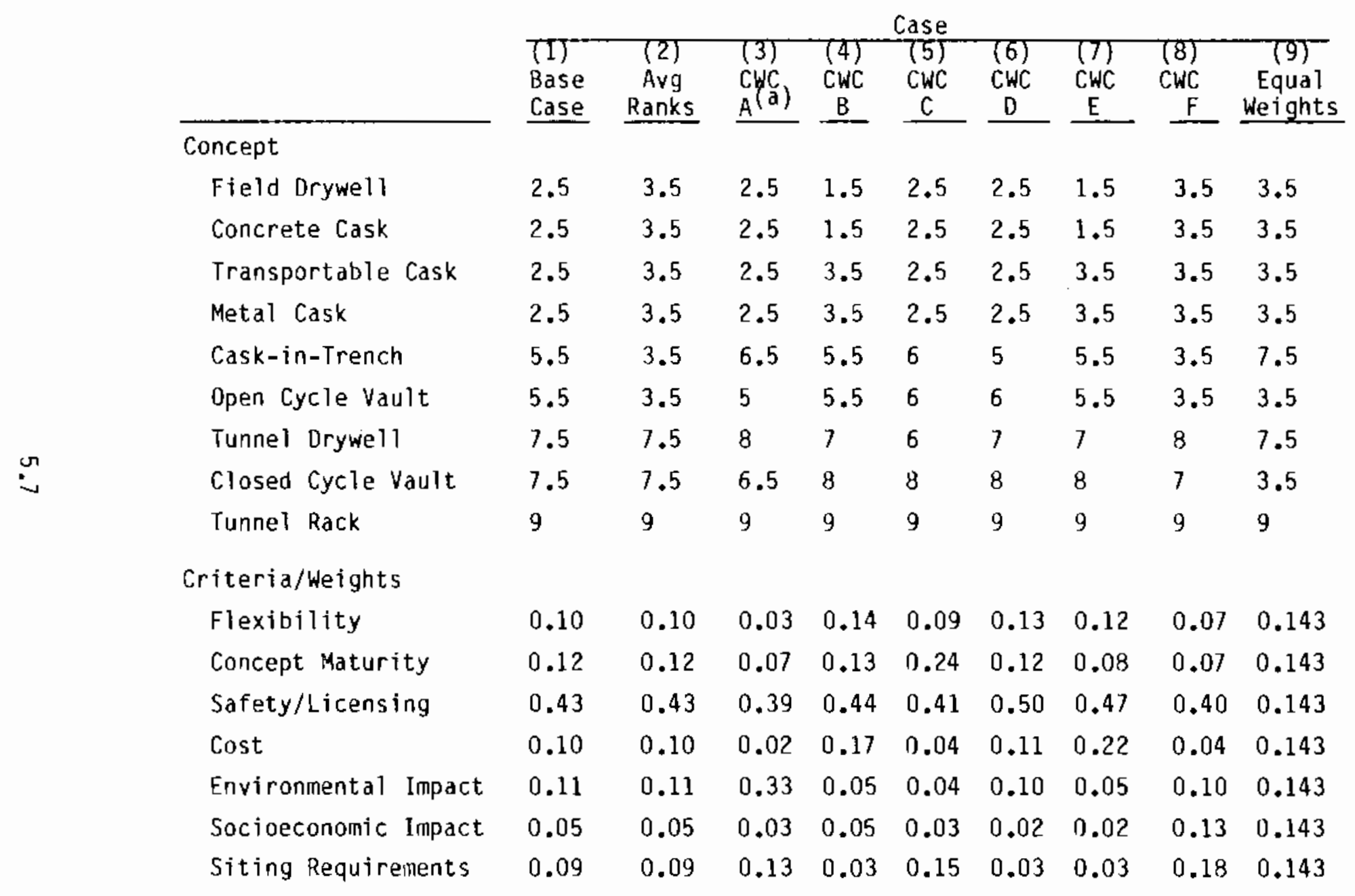

(a) Criteria Weighting Committee, member "A". 


\subsection{PAIRWISE COMPARISON OF CONCEPTS - FINAL RANKING}

The top concepts did have differences in their relative merits as an MRS facility. Each concept had some advantages and disadvantages when compared with any other concept. The purpose of these comparisons was to clearly identify and discuss these differences and to determine the relative significance of the tradeoffs among concepts. These comparisons were made by sequentially examining each pair of the six top concepts. Concept ranking committee members discussed in depth the significance of each tradeoff and selected the most preferred concept of each pair. Then, on the basis of the discussions and pairwise comparison results, the committee developed a final preference ordering of concepts and the associated rationale to document the results. The primary and alternate concepts were chosen as the first and second concepts, respectively, in this final preference ordering. The ordering for the top six concepts after pairwise evaluation was:

- Field Drywell

- Concrete Cask

- Open Cycle Vault

- Metal Cask - Stationary

- Metal Cask - Transportable

- Concrete Cask-In-Trench

FIELD DRYWELL

The field drywell concept is recommended for further design study because of its extensive operational experience, low cost, and simple, flexible design. Its principal advantages are the following:

- The field drywell has 10 to 15 years of operational experience (Anderson and Meyer 1980) and a large accumulation of experimental data (Unterzuber et a1. 1982) from operations. As a result, there is good confidence in the predicted performance for such factors as heat remova1, containment, and the estimated construction and operations costs. This experience lends confidence that a facility could be designed, constructed, and licensed in a timely manner, should Congress authorize its construction. 
- It provides a high degree of flexibility and readily accommodates changing capacity requirements by permitting very small (one drywell) incremental additions to the storage arrays, and rapid random access to any of the storage units if retrieval is needed.

- The field drywell is the least expensive of all concepts over the postulated life cycle. Its cost is also relatively insensitive to type of fuel stored, whether spent fuel or reprocessing waste.

- It has a much smaller visual impact than do most of the other concepts.

- Since only one canister of spent fuel or reprocessing waste is stored in each drywell, leakage of a canister would not result in contamination of other canisters in storage; facility operation would not be disrupted by leakage from a single canister.

The principal disadvantages of the field drywell concept result from its emplacement into the ground and its interaction with site characteristics. These disadvantages are:

- Site selection must take into account characteristics required to ensure proper drywell operation, including heat removal (soil conductivity) and hydrological characteristics. These restrictions are not perceived as too severe, since an engineered berm could be constructed to ensure consistent soil characteristics and alleviate water intrusion problems.

- Since the drywell is set into the ground, it may be perceived to be more permanent than the moveable storage devices and, therefore, less desirable in the eyes of the local poputace.

- The land requirement of the drywell concept ( 180 acres) is somewhat larger than most other concepts.

- One handiing operation (emplacement) of storage canisters takes place outside the confines of the Receiving and Handling facility. 


\section{CONCRETE CASK}

The concrete cask concept is recomnended for further design study because of its demonstration experience, simple and flexible design, and low estimated cost compared to the other concepts. Its principal advantages are the following:

- Its extensive demonstration experience and accumulation of experimental data provide assurance of safe and reliable operations, accurate estimated construction and operations costs, and ease of licensing.

- It is the second least expensive concept over the postulated life cycle, being only slightly more expensive than the field drywell concept. (a) Its cost is also essentially insensitive to the material being stored, whether spent fuel or reprocessing waste.

- Incremental additions as sma11 as one cask can be made to the storage arrays, and random access to each cask is possible when needed. Unlike the field drywell, storage canisters are not handled outside of the R\&H facility.

- Casks are moveable and placed on pads on the surface of the ground. Consequently, the concrete cask concept is relatively independent of site characteristics and may be perceived as being less permanent than other concepts.

The principal disadvantages of the concrete cask concept are the following:

- An array of concrete casks will have a large visual impact, since the casks are $\sim 3 \mathrm{~m}$ in diameter and $\sim 6 \mathrm{~m}$ in height. The land area required for storing 15,000 MTU of spent fuel, including support facilities, is 130 acres, slightly above average for the concepts that were considered.

(a) Cost analyses performed by the normalization contractors gave a lifecycle cost of $\$ 650 \mathrm{M}$ for the field drywell concept and $\$ 820 \mathrm{M}$ for the concrete cask concept. Later examination of the analyses showed some differences in assumptions, that, if eliminated, would make the cost difference between the two concepts less than $5 \%$. 
- The size and weight of the casks makes an onsite cask fabrication plant almost a necessity, thus increasing the number of onsite support facilities.

- Casks are stored above-ground in open fields and thus would be more susceptible than most other concepts to intrusions or sabotage.

\section{OPEN CYCLE VAULT}

The open cycle vault concept has desirable features for an MRS facility. of the vault concepts considered in this evaluation, it is the most mature and least complex. However, it is not recommended as one of the two concepts for further design because it is less mature and more complex than either the field drywell or concrete cask. In addition, it has a significant cost disadvantage relative to the selected concepts. Its principal advantages are the following:

- Vaults in the U.S. at INEL and in the U.K. at Wyfla have provided a significant base of operating experience. Recent design analyses and experimental studies by National Nuclear Corporation, Ltd, provide good confidence in the predicted heat removal performance.

- The open cycle vault concept is quite flexible. Storage capacity can be added in increments corresponding to about one-fifth of 1 year's required throughput capacity. Rapid, random access to all storage locations is possible if retrieval is necessary. In addition, this concept is the least sensitive of all of the concepts to increased heat loads in the stored material.

- The vault is located in an engineered surface facility. Its design and operations are relatively independent from site characteristics. It is about average in land usage ( 100 acres for a 15,000 MTU capacity facility).

- The enclosed structure of the vault makes unauthorized access to stored material more difficult than concepts that array casks or drywells in open fields. 
- The estimated life-cycle cost for the vault is insensitive to the type of storage, whether spent fuel or reprocessing waste.

The principal disadvantages of the open cycle vault concept are the following:

- Its life-cycle cost is estimated to be about one-quarter more than that for the field drywell and concrete cask.

- The vault has somewhat more operational complexity and less experience than either the field drywell or concrete cask. Relative to the top two concepts, the open cycle vault provides less assurance of licensability.

- The large vault structure may be perceived to be more permanent than the moveable storage devices and thus may be less desirable in the eyes of the local populace.

METAL CASK (STATIONARY)

The stationary metal cask concept builds upon extensive experience with transport casks and thus provides assurance of flexible, safe, and reliable operations. Its major drawback, relative to the concepts ranked above it, is its significantly higher cost. The principal advantages of the stationary metal cask concept are the following:

- Many years of experience have been accumulated with metal casks for transport of spent fuel. As a result, there is considerable experience in the fabrication of metal casks, and the confidence in the estimated construction and operations costs is high.

- The metal cask concept demonstrates a high degree of flexibility, since storage capacity can be added in units of one cask, and rapid random access to each cask is possible if retrieval is necessary. In addition, no storage canister handling operations take place outside the confines of the R\&H facility.

- Since it is located above ground, the metal cask is relatively independent of site characteristics. It is about average in terms of 
land usage ( 100 acres), and may be perceived to be less permanent than in-ground concepts or concepts requiring large engineered structures.

The principal disadvantages of the stationary metal cask concept are the following:

- Its estimated life-cycle cost is nearly twice that of the field drywell and the concrete cask.

- Its costs are quite sensitive to the material being stored, spent fuel or reprocessing waste, and to the heat loads of the stored material.

- Like other surface cask concepts, metal casks are open and exposed and thus have a high visual impact and are more susceptible to intrusion or sabotage than are in-ground storage concepts.

\section{METAL CASK (TRANSPORTABLE)}

The transportable metal cask concept, evaluated for use in a stand-alone MRS facility, has many of the same advantages and disadvantages as the stationary metal cask. In combination with any of the other storage concepts, it improves the overall flexibility of the MRS system by accommodating any efforts that utilities may make to expand their at-reactor storage capacity through the use of metal casks. However, this latter case was not evaluated.

Relative to the stationary metal cask concept, the transportable metal cask concept has the following principal advantages:

- It has a lower estimated life-cycle cost resulting from the smaller R\&H facility, which is only required to handle decontamination and repair of leaking canisters, plus routine handling, inspection and washdown of the casks.

- Because the transportable metal storage cask is used to transport fuel by rail from reactor sites to the MRS site and from the MRS site to its ultimate destination, no additional transport casks are needed. (The economic advantage of this reduction in the number of 
casks has not been included in the life-cycle cost estimate since system costs external to the MRS facility are not considered in these analyses.)

- It permits receipt of metal casks used by utilities for at-reactor storage, without transfer to a new storage device.

Its principal disadvantage relative to the stationary metal cask concept is the following:

- Consolidation of spent fuel is necessary to minimize the number, and hence the cost, of the storage modules. This results in the need for installation and operation of consolidation equipment at each reactor site. Otherwise, the fuel would have to be untoaded and consolidated at the MRS site, thus negating one of the principal advantages of the transportable cask--the elimination of processing at the MRS site and the reduction in size and scope of the R\&H facility. Without consolidation, approximately twice as many transportable storage casks would be required, significantly increasing costs.

\section{CONCRETE CASK-IN-TRENCH}

The concrete cask-in-trench concept shares many of same features as the concrete surface cask concept. The demonstration experience with the concrete surface cask concept lends confidence to the cost estimates for the cask-intrench concept and some assurance of its reliable operation. As with the concrete cask concept, it may be desirable with the cask-in-trench concept to locate a cask fabrication facility onsite to minimize handling of the new casks. The principal advantages of the cask-in-trench relative to the concrete surface cask concept are the following:

- The subsurface casks are less vulnerable to damage from natural or man-caused events than the surface casks.

- Since casks are set into the ground, the visual impact of such a facility is much less than for the surface casks.

The principal disadvantages of the concrete cask-in-trench concept relative to the concrete surface cask concept are the following: 
- Its estimated life-cycle cost is the highest of all the candidate concepts-more than twice the estimated cost of the field drywell.

- Its land usage ( 360 acres for a 15,000 MTU capacity facility) is nearly three times that of the concrete surface cask.

- Retrieval of a cask is more difficult than for the concrete surface cask due to the need for excavation around a selected cask prior to removal from storage.

\section{CLOSED CYCLE VAULT}

The closed cycle vault concept is most similar to the open cycle vault concept in that both use large engineered surface structures to house the stored material. Relative to the open cycle vault concept, the closed cycle vault concept is a more complex and less mature system. Its principal advantages are the following:

- Its design and operation are relatively independent of the site characteristics.

- Rapid random access to all storage locations is possible when necessary.

- Incremental additions to storage capacity can be made in units of one module.

The principal disadvantages of the closed cycle vault concept are the following:

- It lacks demonstration or operating experience. As a result, confidence in the predicted heat removal performance is not as high as with most other concepts, and, until the concept has been demonstrated, licensing may be difficult.

- The estimated life-cycle cost is about one and one-half that estimated for the field drywell.

- The sensitivity of the life-cycle cost to the material stored, whether spent fuel or reprocessing waste, is relatively large. 
TUNNEL DRYWELL

The tunnel drywell and field drywell concepts share many of the same features. In particular, the tunnel drywell has an extensive base of operational experience (at the Nevada Test Site), which provides confidence in its operational characteristics, including heat removal. There is also reasonable confidence in estimated construction and operating costs. Relative to the field drywell concept, the tunnel drywell concept has the following principal advantages:

- With the drywells contained in tunnels, there is essentially no visual impact from the storage portion of the facility.

- Storage locations are easily secured against intrusion. The principar disadvantages of the tunnel drywell concept relative to the field drywell concept are the following:

- Due to the need for a mountainside or hillside of capable rock, locations suitable for siting the tunnel drywell would be limited.

- Because stored material would be placed in the ground within tunnels, the tunnel drywell concept could be perceived by some as a nearsurface repository and could encounter problems in finding an institutionally acceptable site.

- Construction of tunnels causes additional interaction with the site. Spoils piles would need to be handled, and recovering the site after the need for MRS has passed would be relatively more difficult. The tunnels lend an additional air of "permanence" to a temporary storage facility.

- Its estimated life-cycle cost is roughiy $88 \%$ greater than that of the field drywell.

- Its land usage ( 800 acres for a 15,000 MTU capacity facility) is the highest of all the concepts. 
TUNNEL RACK VAULT

The tunnel rack vault concept is the least mature and most complex of the candidate concepts. Consequently, it would likely require the greatest effort in assuring and demonstrating safe, reliable operations. Its principal advantages are the following:

- With the storage locations within tunnels, there is essentially no visual impact from the storage area.

- The storage locations are easily secured against intrusion.

- Its estimated life-cycle cost is only about one-third greater than that of the field drywell, and its cost is relatively insensitive to the material stored, whether spent fuel or reprocessing waste.

- The projected land usage for the tunnel rack vault is the smallest of all the concepts (less than 90 acres), about two-thirds that needed for the concrete cask.

The principal disadvantages of the tunnel rack vault concept are the following:

- The lack of demonstration and operating experience leads to lower confidence in heat removal performance and estimated life-cycle cost than for most other concepts.

- The complexity of its operating system--all operations in the storage area must be carried out remotely--leads to lower confidence of safe, reliable operations. Recovery from mechanical maifunctions in the storage area could be difficult. Until the system has been demonstrated, licensing of this concept may also be difficult.

- Access to stored canisters is slow and sequential, last-in, firstout.

- The canisters are the last barrier between the stored material and the cooling air, which is discharged directly from the storage area to the atmosphere. 


\subsection{CONCLUSIONS AND RECOMMENDATIONS}

Evaluation of the candidate concepts indicates that all of the concepts could satisfactorily serve in an MRS facility. However, using the seven criteria mentioned above, the concepts were found to have different degrees of desirability. The most significant bases for selecting from among the concepts are the following:

1. In the role as a back-up to the repository, desirable MRS concepts provide high assurance of deployment and operation by 1998. Simple and mature, or well-understood concepts are preferred. Such concepts pose fewer difficulties for assuring safe, secure operations and are less susceptible to licensing delays or costly design modifications.

2. MRS facilities must be easily adaptable to a wide variety of site conditions. A potential source of delay in the repository progran is the uncertainty in interactions between site characteristics and the satisfactory performance of the repository. Desirable MRS facilities minimize the dependence of facility operations on site characteristics.

3. Given the uncertain level of demand for an MRS facility, preference is given to concepts that permit small incremental additions to capacity. Moreover, the temporary nature of MRS suggests that preference also be given to concepts that do not rely on large structures or other engineered components that disrupt the site and imply a degree of "permanence."

4. Relative life-cycle cost provides a significant degree of discrimination among the concepts. Since the DOE is charged with carrying out the NWPA in a cost-effective manner, significant cost differences among concepts are important in selecting the preferred concepts.

Based upon these considerations, the overall ranking from most to least desirable is as follows:

- Fieid Drywell(a)

- Concrete Cask $(a)$

(a) Most preferred concepts. 
- Open Cycle Vault

- Metar Cask (Stationary)

- Metal Cask (Transportable)

- Concrete Cask-In-Trench

- Closed Cycle Vault

- Tunnel Drywell

- Tunnel Rack Vault.

The sensitivity of the above order to realistic variations in the assumed importance of each criterion was examined. The top six concepts were found to be insensitive to these variations. These same six concepts remain at the top, clearly separated from the lower three.

The last three concepts were judged significantly lower in overall performance for the following reasons:

- The closed cycle vault ranked low overall because of its relatively complex, untested, and undemonstrated design.

- The tunnel drywell requires extensive excavation, which limits its flexibility and increases the environmental impact and siting requi rements.

- The tunnel rack vault also lacks testing or demonstration experience and its complexity requires relatively more design conservatism.

The field drywell is recommended because:

- It has an appreciable accumulation of operational experience, lending confidence to its expected performance characteristics (e.g., heat removal and containment), to its assurance of meeting licensing requirements, and to its estimated construction and operation costs.

- It has the lowest undiscounted life-cycle cost, based upon storage of 15,000 MTU of spent fuel.

- It is flexible in that very small incremental additions to storage capacity can be made and rapid random access to any storage unit can be provided if retrieval of the stored waste is required. 
The concrete cask (sealed storage cask) is recommended because:

- It has demonstrated experience, and a significant body of experimental data, which increase confidence in its cost estimates and its important operational characteristics, such as heat removal.

- It has the second lowest undiscounted life-cycle cost, based upon 15,000 MTU of spent fuel.

- It is flexible in that incremental additions to storage capacity of one cask can be made and random access to each cask can be provided. This evaluation compared the performance of each of the candidate MRS concepts in the role of a stand-alone facility. However, the transportable metal storage cask may be used by some utilities to supplement their at-reactor storage until such time as the repository or MRS becomes available. Consequentiy, a hybrid storage facility may be desirable (e.g., one using field drywells or concrete casks, with the capability of receiving and storing the transportable storage cask). Both the field drywell and the concrete cask concepts can easily accommodate the transportable storage cask. Further design efforts should incorporate this capability. 
. 
REFERENCES

Boeing Engineering Company, 1983a. Monitored Retrievable Storage Conceptual System Study: Concrete Storage Casks. BEC-MRS-3302, Seattle, Washington.

Boeing Engineering Company. 1983b. Monitored Retrievable Storage Conceptual System Study: Cask-In-Trench. BEC-MRS-3303, Seattle, washington.

Boeing Engineering Company. 1983c. Monitored Retrievable Storage Conceptual System Study: Open Cycle Vault. BEC-MRS-3304, Seattle, Washington.

Cook, W. D., and L. M. Seiford. 1978. "Priority Ranking and Consensus Formation." Management Science. 24(16):1721-1732.

Department of Energy. 1983. The Monitored Retrievable Storage Proposal Research and Development Report. DOE/S-0021, Washington, D.C.

GA Technologies, Inc. 1984a. Monitored Retrievable Storage Conceptual System Study: Closed-Cycle Vault. GA-A17322, San Diego, California.

GA Technologies, Inc. 1984b. Monitored Retrievable Storage Conceptual System Study: Tunnel-Rack Vault. GA-A17323, San Diego, California.

Raymond Kaiser Engineers, Inc. 1984. Monitored Retrievable Storage Conceptual System Study: Dry Receiving and Handling Facility. KEHR-83-96, Issued by Kaiser Engineers Hanford Company, Richland, Washington.

Saaty, T. L. 1980. The Analytic Hierarchy Process. McGraw Hil1, New York, New York.

Westinghouse Electric Corporation. 1983a. Monitored Retrievable Storage Conceptual System Study: Metal Storage Casks. WTSD-TME-010, Pittsburgh, Pennsyivania.

Westinghouse Electric Corporation. 1983b. Monitored Retrievable Storage Conceptual System Study: Open Field Drywells. WTSD-TME-011, Pittsburgh, Pennsylvania.

Westinghouse Electric Corporation. 1983c. Monitored Retrievable Storage Conceptual System Study: Tunnel Drywel1s. WTSD-TME-012, Pittsburgh, Pennsylvania.

Westinghouse Electric Corporation. 1983d. Monitored Retrievable Storage Conceptual System Study: Transportable Storage Casks. WTSD-TME-013, Pittsburgh, Pennsylvania. 


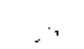




\section{DISTRIBUTION}

No. of

Copies

OFFSITE

6 B. C. Rusche

Office of Civilian Radioactive Waste Management

U.S. Department of Energy

$\mathrm{RW}-1$

Washington, DC 20545

R. H. Baver

Office of Civilian Radioactive Waste Management

U.S. Department of Energy

RW-30

Washington, DC 20545

K. A. Klein

Office of Civilian Radioactive

Waste Management

RH-31

U.S. Department of Energy

Washington, DC 20545

J. H. Carlson

Office of Civilian Radioactive Waste Management

U.S. Department of Energy

RH-32

Washington, DC 20545

27 DOE Technical Information Center

F. L. Harris

Raymond Kaiser Engineers

P.0. Box 23210

0akland, CA 94623-2321

G. P. Osborne

Kaiser Engineers Hanford Co.

P.0. Box 888

Richland, WA 99352
No. of

Copies

R. J. Steffen

Storage Technology Projects

Westinghouse Electric Corp.

P.ú. Box 10864

Pittsburgh, PA 15236-0864

A. P. Abel

Boeing Engineering Co.

P.0. Box 3707

Seattle, WA 98124

B. J. Baxter

GA Technologies, Inc.

P.0. Box 81608

San Diego, CA 92138

R. M. Jefferson

Sandia National Laboratories

Transportation Technology Center

P.0. Box 5800

Albuquerque, NM 87185

G. C. Allen

Sandia National Laboratories

Transportation Technology Center

P.0. Box 5800

Albuquerque, NM 87185

R. S. Waters

DOE Salt Repository Project Office

$505 \mathrm{King}$ Ave.

Columbus, $\mathrm{OH} 43201$

ONSITE

4 DOE Richland Operations Office

P. A. Craig (2)

R. B. Goranson

H. E. Ransom 
No. of

Copies

79 Pacific Northwest Laboratory

F. W. Albaugh

K. R. Ames

W. B. Ashton

W. W. Ballard

D. E. Blahnik

S. H. Bush

J. F. Fletcher

J. J. Fuquay

R. J. Hall (40)

P. L. Hendrickson

D. S. Jackson

W. S. Kelly

D. K. Kreid

R. C. Lijkala

J. D. Ludwick

H. D. Massey
No. of

Copies

P. N. McDuffie

J. L. McElroy

D. F. Newman

D. R. Payson

W. D. Richmond

L. C. Schmid

K. J. Schneider

M. J. Scott

R. L. Shaub

M. J. Sherbin

D. J. Silviera

R. I. Smith (2)

M. B. Triplett (2)

C. M. Unruh

D. G. Watson

Publishing Coordination (2)

Technical Information (5) 